\title{
Phosphorus substituted hydroxylamine and hydroxamic acid derivatives: synthesis and reactivity
}

\author{
Concepción Alonso, Jesús M. de los Santos, Javier Vicario, and Francisco Palacios* \\ Departamento de Química Orgánica I, Facultad de Farmacia y Centro de Investigaciones y \\ Estudios Avanzados “Lucio Lascaray”, Universidad del País Vasco, Apartado 450, \\ 01080 Vitoria-Gasteiz, Spain \\ E-mail: francisco.palacios@ehu.es
}

\section{Dedicated to Prof. Julio Alvarez-Builla on the occasion of his $65^{\text {th }}$ anniversary}

\begin{abstract}
This review summarizes several reports concerning the synthesis and synthetic applications of hydroxylamines derived from phosphines, phosphine oxides and phosphonates, and phosphorus substituted hydroxamic acid derivatives. The first section outlines the synthesis and reactivity of phosphorus $O$-substituted and $N$-substituted hydroxylamines as well as several transformations of phosphorus substituted hydroxylamines including: rearrangement, hydrolysis, reduction and oxidation reactions. The second part of the review covers the synthesis and reactivity of phosphorus $O-, N$-, and $C$-substituted hydroxamic acid derivatives.
\end{abstract}

Keywords: phosphorylated hydroxylamines, phosphorylated hydroxamic acids, rearrangement, hydrolysis, reduction, oxidation, $N$-alkylation, elimination, olefination, radical reaction, cyclization

\section{Contents}

1. Introduction

2. Phosphorus Substituted Hydroxylamine Derivatives

2.1 Synthesis of phosphorus substituted hydroxylamine derivatives

2.1.1 Phosphorus $O$-substituted hydroxylamines

2.1.1.1 Phosphorus-oxygen single bond formation reactions

2.1.1.1.1 Reaction of hydroxylamine derivatives with phosphorylated reagents

2.1.1.1.2 Reaction of nitroso- and nitroxyl derivatives with phosphorus reagents

2.1.1.2 Nitrogen-oxygen bond formation reactions

2.1.2 Phosphorus $N$-substituted hydroxylamines 
2.1.2.1 Phosphorus-nitrogen single bond formation reactions

2.1.2.1.1 Reaction of hydroxylamine derivatives with phosphorus reagents

2.1.2.1.2 Reaction of nitroso compounds with phosphorus reagents

2.1.2.1.3 Rearrangement reactions

2.1.2.2 Carbon-nitrogen single bond formation reactions

2.2 Reactivity of phosphorus substituted hydroxylamine derivatives

2.2.1 Phosphorus $O$-substituted hydroxylamines

2.2.1.1 Rearrangement reactions

2.2.1.2 Hydrolysis reactions

2.2.1.3 Reduction reactions

2.2.1.4 Electrophilic amination

2.2.1.5 Oxidation reactions

2.2.2 Phosphorus $N$-substituted hydroxylamines

2.2.2.1 Rearrangement reactions

2.2.2.2 Hydrolysis reactions

2.2.2.3 $\mathrm{N}$-Alkylation reactions

2.2.2.4 Oxidation reactions

2.2.2.5 Elimination reactions

3. Synthesis and Reactivity of Phosphorus Substituted Hydroxamic Acid Derivatives

3.1 Phosphorus $O$-substituted hydroxamic acid derivatives

3.2 Phosphorus $N$-substituted hydroxamic acid derivatives

3.3 Phosphorus $C$-substituted hydroxamic acid derivatives

4. Acknowledgments

5. References

\section{Introduction}

Hydroxylamines have been extensively reviewed ${ }^{1}$ and compounds with $\mathrm{N}-\mathrm{O}$ linkage in their structure have been found to be an important class of chemical species due to their biological activity. Hydroxylamine derivatives have also become important as intermediates for synthesizing complex nitrogen-containing compounds, especially natural products and their analogues. $^{2}$ Such derivatives are found among iron sequestering siderophores, ${ }^{3}$ inhibitors of 5lipoxygenase, ${ }^{4}$ DXP reductoisomerase, ${ }^{5}$ and metalloproteinase. ${ }^{6}$

On the other hand, the chemistry of hydroxamic acids has also been reviewed. ${ }^{1}$ In general, hydroxamic acid derivatives have attracted considerable interest because of their activity in inhibiting medically important enzymes such as metalloproteases ${ }^{7}$ and lipoxygenases. ${ }^{8}$ Phosphorus compounds have also shown to exhibit biological activity in various areas by virtue of their analogy to naturally occurring compounds. However, to date there are only a few reports in the literature on the combination of the phosphorylated ${ }^{9-11}$ and hydroxylamine and/or hydroxamic functions in a molecule. 


\section{Phosphorus Substituted Hydroxylamine Derivatives}

\subsection{Synthesis of phosphorus substituted hydroxylamine derivatives}

In this section we consider phosphorus functionalized hydroxylamines derived from phosphines, phosphine oxides, phosphonates, etc. We first focus on the synthesis of phosphorus $O$-substituted hydroxylamines I and phosphorus $N$-substituted hydroxylamines II (Figure 1), after which their reactivity will be discussed.<smiles>CN(C)O[C+]1CCCC1</smiles>

I<smiles>[R]ON(C)c1ccccc1</smiles>

II
(P) $=\mathrm{PR}_{2}, \mathrm{P}(\mathrm{O}) \mathrm{R}_{2}, \mathrm{P}(\mathrm{O})(\mathrm{OR})_{2}$, etc.

\section{Figure 1}

2.1.1 Phosphorus $\boldsymbol{O}$-substituted hydroxylamines. Several strategies have been developed for the preparation of phosphorus $O$-substituted hydroxylamines, such as phosphorus-oxygen single bond formation either by reaction of hydroxylamines and phosphorylated halides (Scheme 1, Route $\mathrm{a}_{1}$ ) or by reaction of nitroso or nitroxyl derivatives and phosphorus reagents (Scheme 1, Route $\mathrm{a}_{2}$ ), and by oxidation reactions where a nitrogen-oxygen single bond is formed (Scheme 1 , Route b).

\section{P-O Bond Formation}

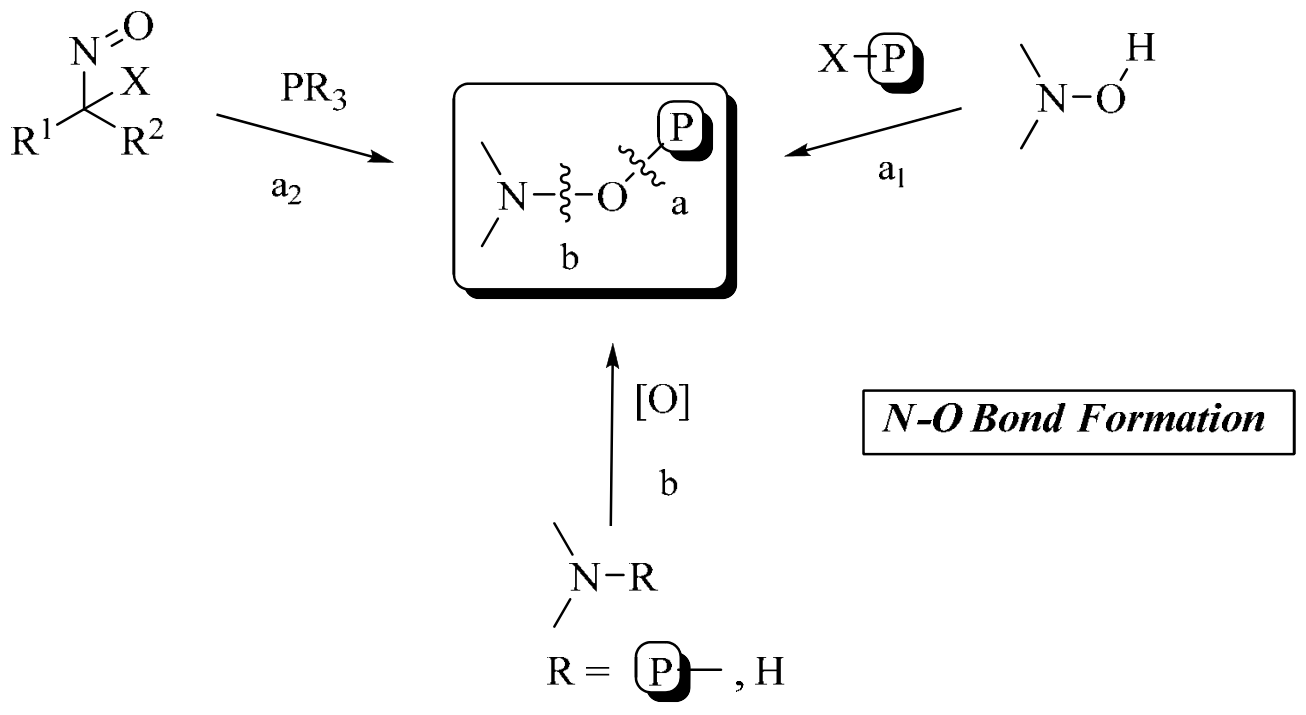

\section{Scheme 1}




\subsubsection{Phosphorus-oxygen single bond formation reactions (Scheme 1a)}

2.1.1.1.1 Reaction of hydroxylamine derivatives with phosphorylated reagents (Scheme $1 \mathrm{a}_{1}$ ). $N, N$-Disubstituted and $N$-monosubstituted $O$-phosphinyl hydroxylamines 3 have been prepared by reaction of the corresponding hydroxylamines $\mathbf{2}$ and diphenylphosphinyl chloride $\mathbf{1}$ in the presence of a base (Scheme 2). ${ }^{12,13}$

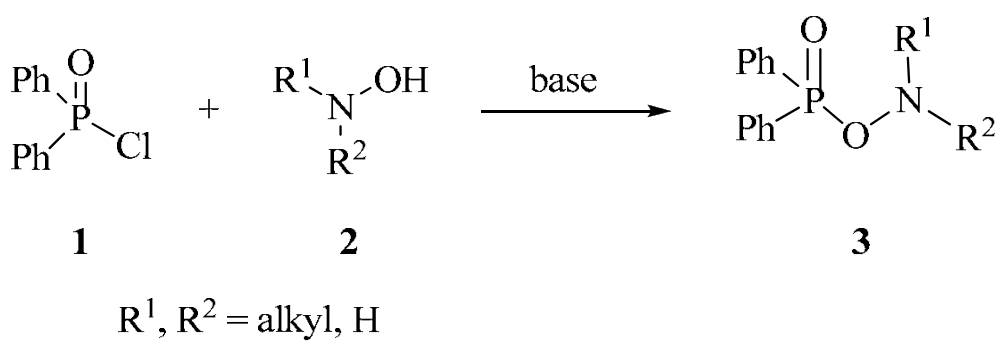

\section{Scheme 2}

This process has been applied for the preparation of precursors of proline derivatives ${ }^{14}$ involving the cyclization of 5 -aminovaleric acid derivatives. The reaction of $N$-substituted hydroxylamines with 5-bromovalerate esters gave 5-( $N$-hydroxyamino) esters 4 , and the subsequent reaction with diphenylphosphinyl chloride $\mathbf{1}$ in the presence of triethylamine afforded hydroxylamine derivatives 5 in good yields (Scheme 3 ). ${ }^{12 \mathrm{e}, 13 \mathrm{~b}}$

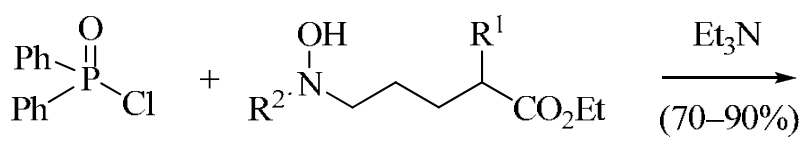

1<smiles>[R]C(CCCN([R])OP(=O)(c1ccccc1)c1ccccc1)C(=O)OCC</smiles>

5

\section{Scheme 3}

$\mathrm{N}$-Vinylhydroxylamine $6\left(\mathrm{X}=\mathrm{CH}_{2}\right)$ can be used as starting material for the preparation of phosphorus functionalized hydroxylamines, and, when it reacts with diethyl chlorophosphate 8 , $O$-phosphoryl hydroxylamine derivative $\mathbf{9}$ is obtained (Scheme 4). Similarly, the process is also extended to the preparation of the heterocyclic functionalized hydroxylamine compound $\mathbf{1 0}$ from pyrimidone derivative $7(\mathrm{X}=\mathrm{MeN}){ }^{15}$ 

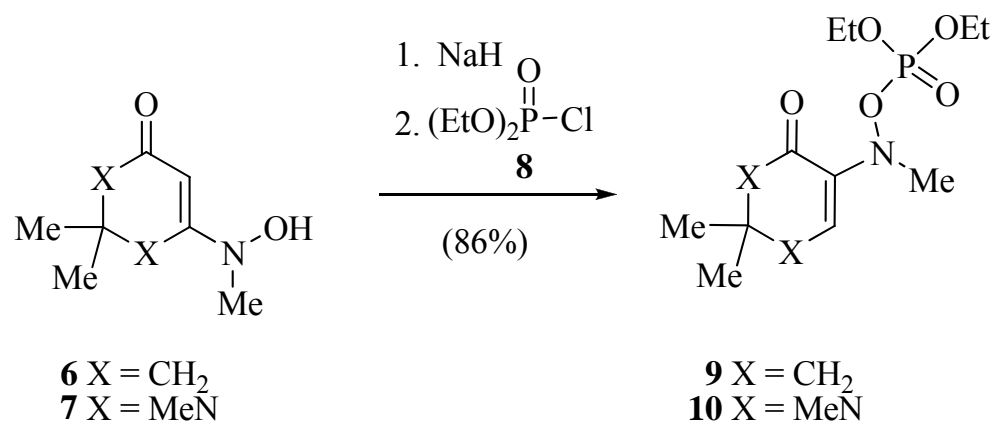

\section{Scheme 4}

Chiral aminating reagents 13 are prepared in a 'one-pot' process from ephedrine 11, $N, N$ dimethylhydroxylamine and phosphorus oxychloride by means of nucleophilic substitution of 12 with $N, N$-dimethylhydroxylamine, with retention of configuration at the phosphorus atom (Scheme 5). ${ }^{16}$ These compounds are used (see Section 2.2.1.4) for selective $\mathrm{C}-\mathrm{N}$ bond construction.<smiles>CN[C@@H](C)[C@H](O)c1ccccc1</smiles>

$11 \mathrm{a}$<smiles>CN[C@@H](C)C(O)c1ccccc1</smiles>

$11 \mathbf{b}$

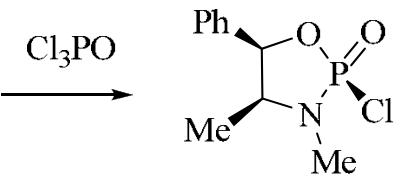

$(-)-(S, R)-\mathbf{1 2 a}$<smiles>CC1[C@H](c2ccccc2)O[P+](Cl)(Cl)N1C</smiles>

$(+)-(S, S)-\mathbf{1 2 b}$

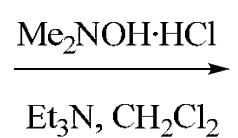

$(68 \%)$

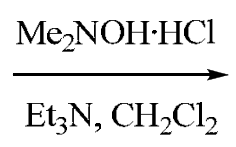<smiles>CC1C(c2ccccc2)OP(=O)(ON(C)C)N1C</smiles>

$(+)-(R, S)-\mathbf{1 3 b}$

\section{Scheme 5}

Similarly, when optically active hydroxylamines $\mathbf{1 4}$ react with diethyl chlorophosphate $\mathbf{8}$ diethyl hydroxylamino phosphate derivatives 15 are obtained (Scheme 6). ${ }^{17}$ By this methodology the stereochemistry of bis( $N$-phenylethyl)hydroxylamine derivatives $\mathbf{1 4}$ was determined. 
<smiles>[M]C(c1ccccc1)N(O[P+](=O)OCCOCCOCC)c1ccccc1</smiles>

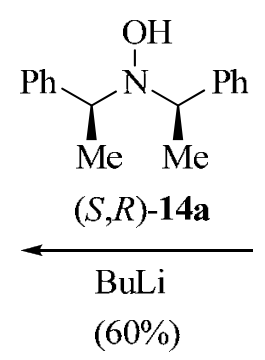

$(60 \%)$<smiles>[M]C(c1ccccc1)N(O)C(=O)COP(=O)(Cl)OCC</smiles>

8<smiles>CC(c1ccccc1)N(O[P+](=O)OCc1ccccc1)C(C)c1ccccc1</smiles>

$(R, R)-\mathbf{1 5 b}$

\section{Scheme 6}

Phosphorylating agents derived from 1-hydroxybenzotriazole 17 can readily be prepared by reaction with phosphorylated halides. In this way, phosphorus substituted benzotriazole derivatives 18 were prepared and subsequently used in the synthesis of activated nucleotides and their phosphorothioate and phosphorodithioate analogues (Scheme 7), useful intermediates in the preparation of $N$-methylphosphoramidates. ${ }^{18}$

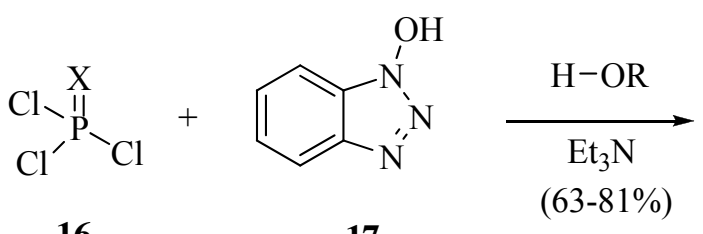

16

17

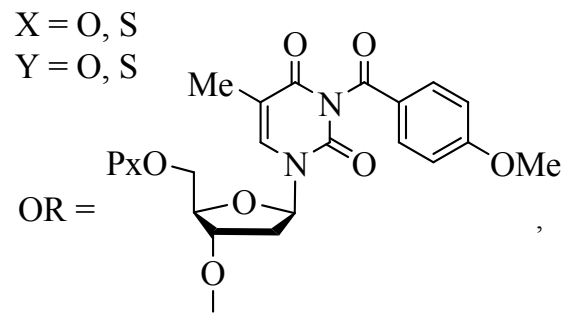

Px $=9$-phenylxanthen-9-yl<smiles>[R20][Y]([Y])([R])On1nnc2ccccc21</smiles>

18<smiles>CCCNc1ncnc2c1ncn2C(COC)OC(=O)COC</smiles>

\section{Scheme 7}

Hydroxylamine can also react with phosphates, and therefore corresponding phosphorylated hydroxylamines are obtained. In this way, Nome et al. have reported the nucleophilic substitution reactions of methylated hydroxylamines with bis(2,4-dinitrophenyl)phosphate (BDNPP) 19. ${ }^{19} \mathrm{~N}$-Mono- and $\mathrm{N}, \mathrm{N}$-dimethylation of hydroxylamine does not significantly affect rates of initial attack of $\mathrm{MeNHOH}$ and $\mathrm{Me}_{2} \mathrm{NOH}$ on BDNPP, which is largely performed by oxygen phosphorylation (Scheme 8). 


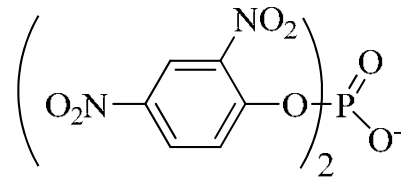

19

BDNPP
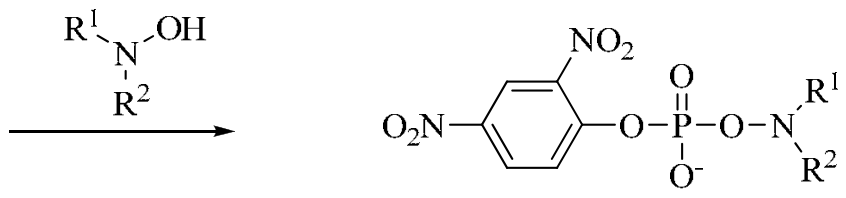

$20 \mathrm{R}^{1}=\mathrm{H}, \mathrm{R}^{2}=\mathrm{Me}$

$21 \mathrm{R}^{\mathrm{I}}=\mathrm{R}^{2}=\mathrm{Me}$

\section{Scheme 8}

\subsection{Reaction of nitroso- and nitroxyl derivatives with phosphorus reagents (Scheme}

1a $\mathbf{a}_{2}$ ). Reaction of trifluoronitrosomethane 22 with tris(trifluoromethyl)phosphine affords phosphine oxide derivative $\mathbf{2 4},{ }^{20}$ whose formation is explained by an initial generation of bis(trifluoromethyl)nitroxybis(trifluoromethyl)phosphine 23, followed by the addition of a second molecule of the nitroso compound 22 (Scheme 9).

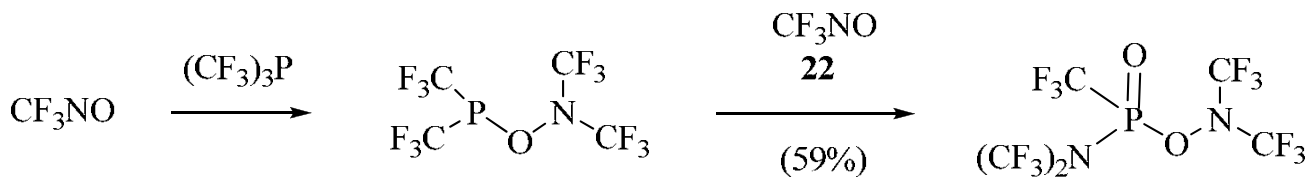

22

23

24

\section{Scheme 9}

Phosphine oxide 27 can be prepared by reaction of bis(trifluoromethyl)phosphinic chloride 25 with mercury (II) bis(trifluoromethyl)nitroxide 26 in excellent yield (Scheme 10). ${ }^{20}$ Nitrosobis derivatives have also been employed in the synthesis of $O$-phosphoryl hydroxylamines. ${ }^{21}$<smiles>O=P(Cl)(Cl)C(F)(F)F</smiles>

25<smiles>CCONC(C)(C)C</smiles>

26

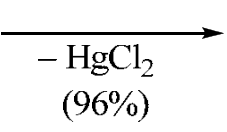

(96\%)<smiles>O=P(ON(C(F)(F)F)C(F)(F)F)(C(F)(F)F)C(F)(F)F</smiles>

27

\section{Scheme 10}

Radical reactions of several phosphines with nitroxyl compounds have been studied (Scheme 11). Several $O$-phosphorus substituted compounds which contain the $N, N$ bis(trifluoromethyl)hydroxylamine moiety are prepared from phosphorus halides as $\mathrm{PF}_{3}, \mathrm{PBr}_{3}$ 
and $\mathrm{PF}_{2} \mathrm{Cl}^{22}$ Moreover, reactions of bis(trifluoromethyl)nitroxide 28 with other phosphorus compounds are varied, and it has been reported to undergo addition-elimination reaction with phosphite $(\mathrm{R}=\mathrm{OMe})^{22}$ and phosphoramide $\left(\mathrm{R}=\mathrm{NMe}_{2}\right)^{22}$ derivatives, affording phosphorus $O$ hydroxylamine derivatives 29, and rather different kind of reactions with phosphine $\mathrm{P}\left(\mathrm{CF}_{3}\right)_{3}$ or halophosphines such as $\mathrm{P}\left(\mathrm{CF}_{3}\right)_{2} \mathrm{X}$ to yield compounds 23,30 in good to excellent yields. ${ }^{23}$

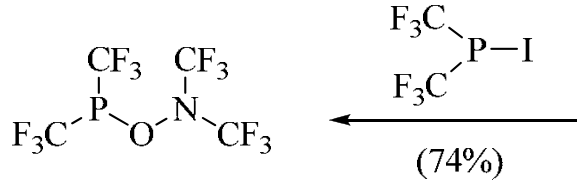

23

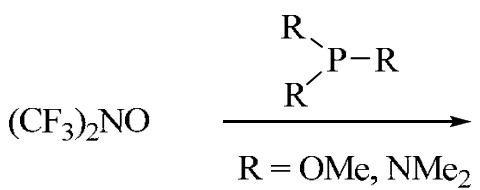

28<smiles>[R][R]([R])ON([Si])C([R])(F)[Si]</smiles>

29

\begin{tabular}{l|l}
$\mathrm{F}_{3} \mathrm{C}_{3}$ \\
$\mathrm{~F}_{3} \mathrm{C}^{\prime} \mathrm{P}-\mathrm{X}$
\end{tabular} \mid $\begin{gathered}\mathrm{X}=\mathrm{F}, \mathrm{Cl}, \mathrm{Br}, \mathrm{CF}_{3} \\
(77-96 \%)\end{gathered}$

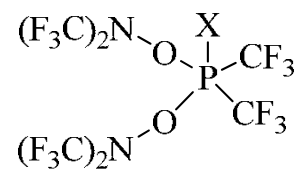

30

\section{Scheme 11}

2.1.1.2 Nitrogen-oxygen bond formation reactions (Scheme 1b). Oxidation of primary and secondary amines 32 with bis(diphenylphosphinyl)peroxide 31 conveniently leads to the $O$ phosphinylated hydroxylamine derivatives 3 (Scheme 12). ${ }^{24}$ Since the peroxide 31 is easily accessible from the diphenylphosphinyl chloride and disodium peroxide, this is an appropriate method for the synthesis of $N, N$-disubstituted and $N$-monosubstituted $O$-phosphinyl hydroxylamines 3 .

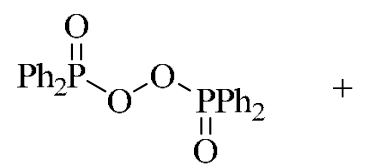

31<smiles>[R]N[R]</smiles>

32

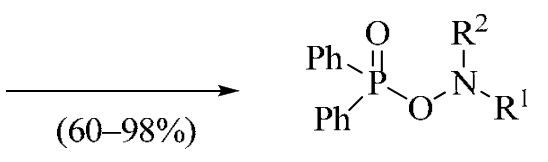

3

$$
\begin{aligned}
& \mathrm{R}^{\mathrm{I}}=\text { alkyl } \\
& \mathrm{R}^{2}=\text { alkyl, } \mathrm{H}
\end{aligned}
$$

\section{Scheme 12}


When phosphoramides react with peracids phosphorus $O$-substituted hydroxylamines are obtained by a radical rearrangement reaction. Dimethyl phosphoramides 33 react with $m$ chloroperbenzoic acid (m-CPBA) to yield novel phosphorus $O$-substituted hydroxylamine derivatives 35 via $\mathrm{N}$-oxidation to $\mathbf{3 4}$ followed by a radical rearrangement with $\mathrm{O}$-insertion into the $\mathrm{P}-\mathrm{N}$ bond (Scheme 13). ${ }^{25}$

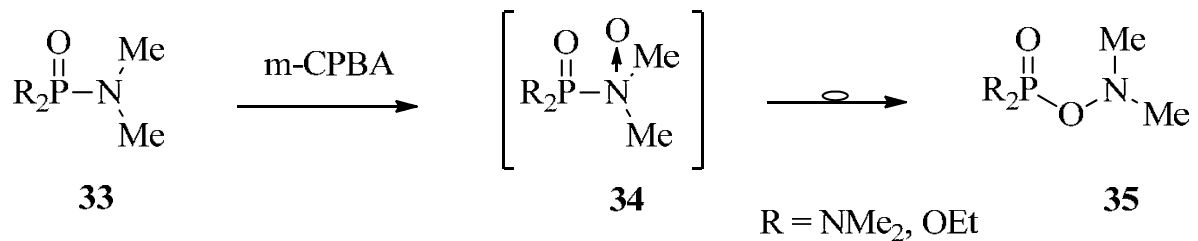

\section{Scheme 13}

Also cyclic phosphinamides react with m-CPBA, as observed for acyclic phosphoramidates. ${ }^{25}$ The reaction of heterocyclic phosphorous derivative 36 with m-CPBA has been performed and the formation of compound 37 could be explained by the replacement of the $\mathrm{P}$-amino by a $\mathrm{P}$-O-amino group through an insertion of oxygen atom between the phosphorus and the nitrogen atoms of the precursor phosphinamide 36 (Scheme 14). ${ }^{26}$<smiles>CNP1(=O)CC=CC1</smiles>

36

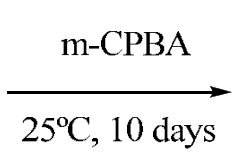

$25^{\circ} \mathrm{C}, 10$ days

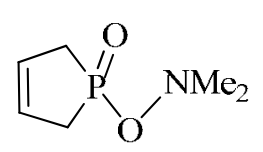

37

\section{Scheme 14}

Nitrogen-oxygen single bond formation reaction occurs also when tetraoxyspiro phosphoranes react with acetylene carboxylates. ${ }^{27}$ The reaction mechanism could be explained by a rearrangement of oxazaspirophosphoranes 38, 39 into the five-membered cycle 40, and subsequent reaction with the acetylenic compound to give the major isomer 41a $(80 \%)$, which upon equilibration affords a mixture of isomers $\mathbf{4 1 a} / \mathbf{4 1 b}$ (45/55\%) (Scheme 15).

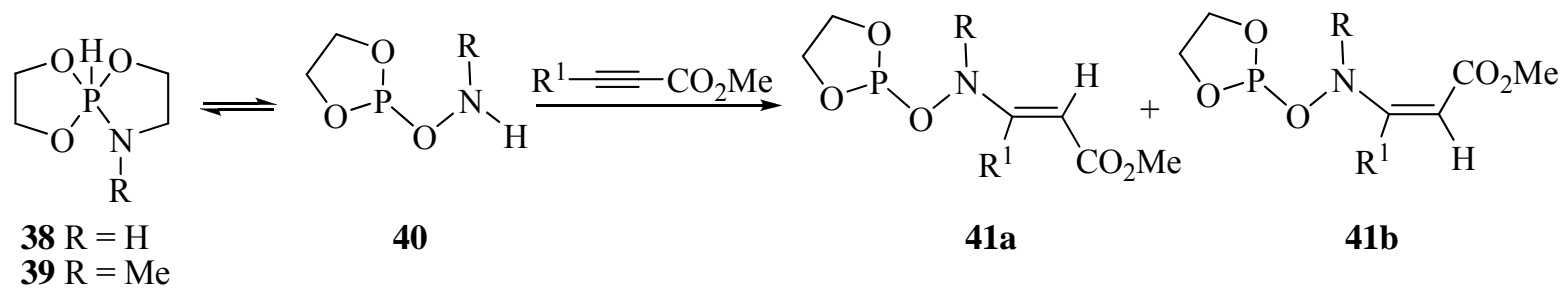

\section{Scheme 15}


2.1.2 Phosphorus $N$-substituted hydroxylamines. The synthesis of $N$-phosphorus substituted hydroxylamines can mainly be approached by two strategies: first, by phosphorus-nitrogen single bond formation reaction between hydroxylamine derivatives or nitroso compounds and phosphorus reagents (Scheme 16, Routes $\mathrm{a}_{1}$ and $\mathrm{a}_{2}$ ) or by rearrangement reactions (Scheme 16, Route $\mathrm{a}_{3}$ ) and second, by carbon-nitrogen single bond formation reaction (Scheme 16, Route b).

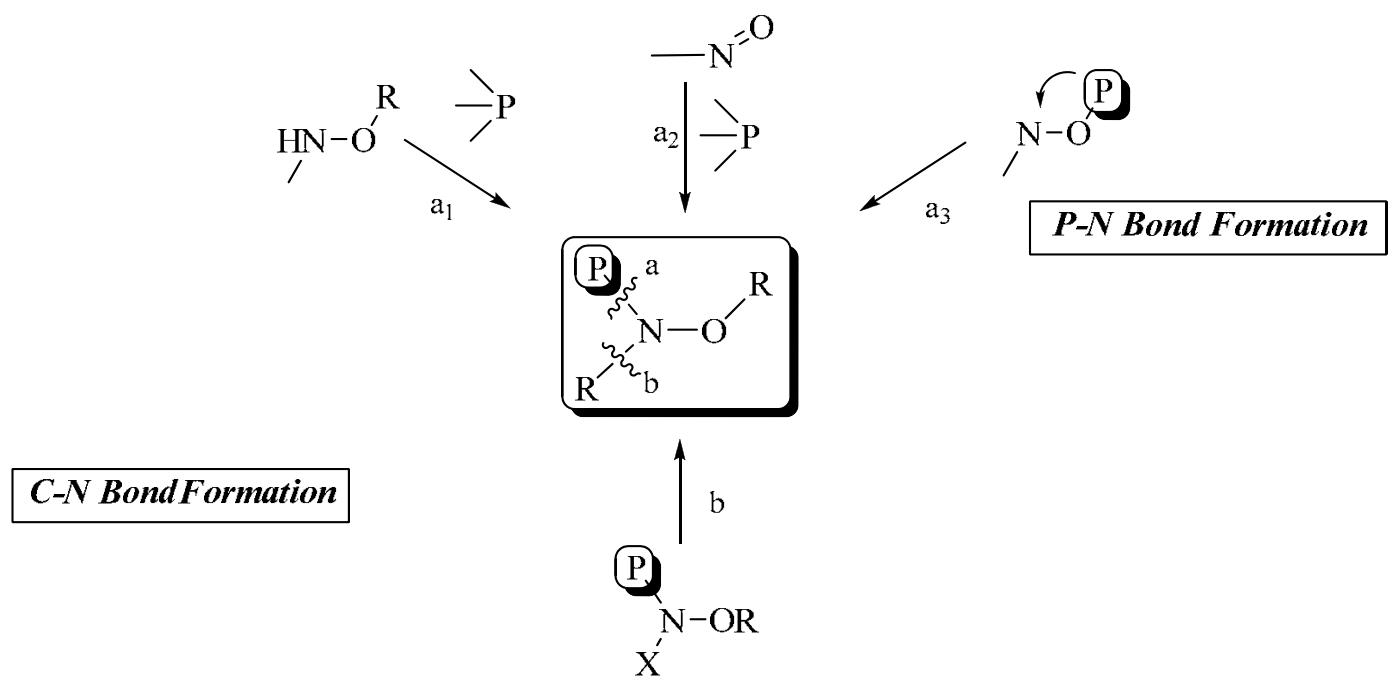

\section{Scheme 16}

\subsubsection{Phosphorus-nitrogen single bond formation reactions (Scheme 16a)}

2.1.2.1.1 Reaction of hydroxylamine derivatives with phosphorus reagents (Scheme 16a $\mathbf{1}_{1}$ ). N,O-Dimethylhydroxylamino halogenophosphines $\mathbf{4 3}$ have been prepared by hydroxylaminolysis reaction of halogenophosphines with $N$-methoxyhydroxylamino derivative 42 (Scheme 17). ${ }^{28}$ It is noteworthy that a restricted $\mathrm{P}-\mathrm{N}$ bond rotation of $\operatorname{bis}(O, N-$ dimethylhydroxylamino)halogenophosphines has been detected. ${ }^{29}$

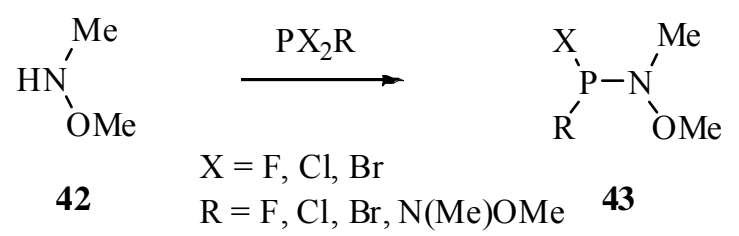

\section{Scheme 17}

Dialkyl $\mathrm{N}$-alkoxyphosphoramidates 46 can be prepared according to the Atherton-Todd method. Diethyl $N$-methoxyphosphoramidate $46\left(\mathrm{R}^{1}=\mathrm{Et} ; \mathrm{R}=\mathrm{Me}\right)$ or diphenyl $N-$ methoxyphosphoramidate ${ }^{31} 46\left(\mathrm{R}^{1}=\mathrm{Ph} ; \mathrm{R}=\mathrm{Me}\right)$ can be obtained from phosphite 44 and the 
corresponding $O$-methylhydroxylamine $(\mathrm{R}=\mathrm{Me})$. However, due to the low yields obtained, a modified procedure, where the concentration of the base is increased and a catalytic amount of triethylbenzylammonium chloride (TEBAC) is used, was developed to afford the $\mathrm{N}$ phosphorylated $O$-alkylhydroxylamines $46\left(\mathrm{R}=\mathrm{Me}, \mathrm{Et}, n\right.$-Bu, Bn, $\left.\mathrm{R}^{1}=\mathrm{Et}\right)($ Scheme 18$)$ in good yields. ${ }^{32}$

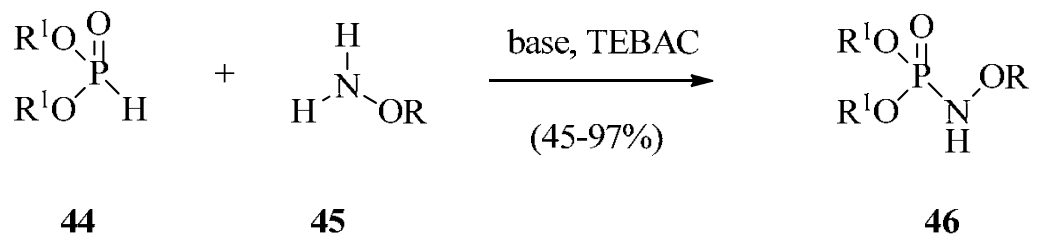

\section{Scheme 18}

Trialkyl phosphites could react with $\alpha$-bromo ketones to give either Arbuzov (phosphonate formation) or Perkow pathway products (enol phosphate formation). Similarly, triethyl phosphite and 3-bromo-1,1,1-trifluoropropane-2-oxime $\mathbf{4 8}$ reacted in a Perkow type reaction with eneoximophosphate formation to yield [N-hydroxy- $N$-(1-trifluoromethylethenyl)]amido diethylphosphate 49 (Scheme 19). ${ }^{33}$

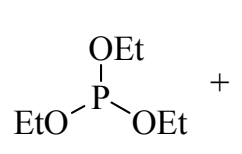

47<smiles>O/N=C(\CBr)C(F)(F)F</smiles>

48

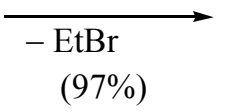

(97\%)<smiles>C=C(N(O)P(=O)(OCC)OCC)C(F)(F)F</smiles>

49

\section{Scheme 19}

Hydroxylamine can also react with phosphates, and therefore the corresponding phosphorylated hydroxylamine are obtained. In this way, Nome et al. have reported the nucleophilic substitution reactions of methylated hydroxylamines with bis(2,4dinitrophenyl)phosphate (BDNPP) ${ }^{19}$ O-Methylation of hydroxylamine blocks the reaction and $\mathrm{H}_{2} \mathrm{NOMe}$ then slowly reacts with BDNPP via $\mathrm{N}$-attack at the phosphorus atom. This is the only example of nitrogen phosphorylation in solution reactions of hydroxylamines with BDNPP. The strong inhibition of the initial reactions by $\mathrm{O}$-methylation when reacted with $\mathrm{H}_{2} \mathrm{NOMe}$ confirms the original assumption that attack on phosphorus is preferentially by the $\mathrm{OH}$ group, although there is a slow reaction with $\mathrm{H}_{2} \mathrm{NOMe}$ forming the $\mathrm{N}$-phosphorylated derivative $\mathbf{5 0}$ (Scheme 20). 

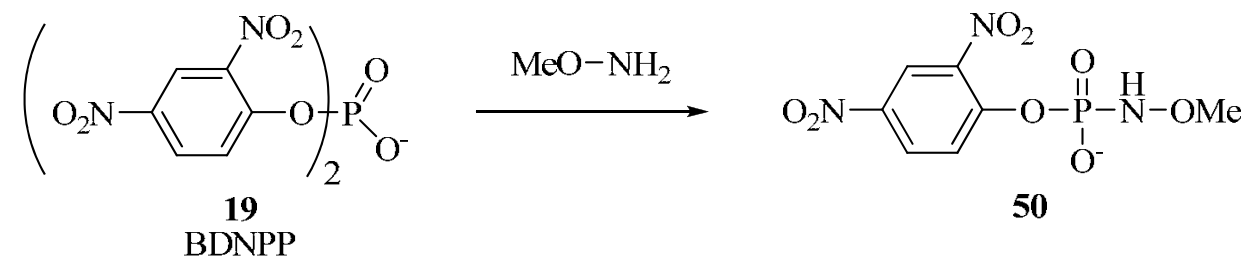

$\mathbf{5 0}$

\section{Scheme 20}

2.1.2.1.2 Reaction of nitroso compounds with phosphorus reagents (Scheme 16a $\mathbf{a}_{2}$ ). Trifluoronitrosomethane 22 reacts with bis(trifluoromethyl)phosphine 51 to give the phosphorylsubstituted hydroxylamine 53, via a $N$-phosphino hydroxylamine intermediate 52 (Scheme 21). ${ }^{20}$

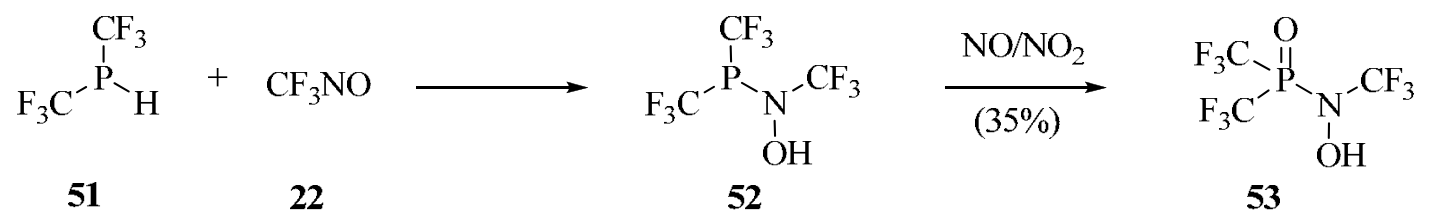

\section{Scheme 21}

Addition of $O$-silylated phosphites 54 to 2-methyl-2-nitrosopropane $55\left(\mathrm{R}^{1}=t\right.$ - $\left.\mathrm{Bu}\right)$ or nitrosobenzene $55\left(\mathrm{R}^{1}=\mathrm{Ph}\right)$ furnished $N$-(trimethylsilyloxy)amidophosphates 57 , via 1,4 trimethylsilyl group shift in intermediate 56 (Scheme 22). ${ }^{33 \mathrm{~b}}$ Trifluoronitrosomethane $55\left(\mathrm{R}^{1}=\right.$ $\left.\mathrm{CF}_{3}\right)$ reacts with different phosphines, among them $(\mathrm{EtO})_{2} \mathrm{POSiMe}{ }_{3}$ or $\left(\mathrm{Me}_{3} \mathrm{SiO}\right)_{3} \mathrm{P}$ to give the corresponding phosphinylhydroxylamine derivatives $57 .{ }^{20}$

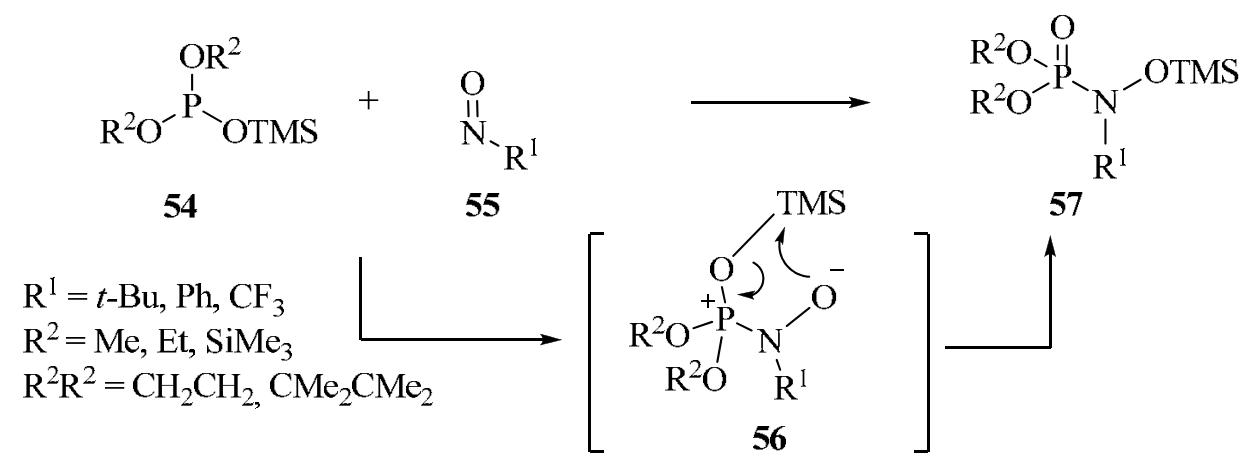

\section{Scheme 22}

2.1.2.1.3 Rearrangement reactions (Scheme 16a $\mathbf{1 0}_{3}$ ). $\mathrm{N}$-Alkyl-O-(diphenylphosphinyl) hydroxylamines 58, whose preparation has been outlined previously (see Section 2.1.1.1.1), 
rearrange on heating, to the thermodynamically more stable $N$-phosphinylated derivatives, the $N$ alkyl- $N$-(diphenylphosphinyl)hydroxylamines 59 (Scheme 23) (see Section 2.2.1.1). ${ }^{34}$<smiles>[R]NOP(=O)(c1ccccc1)c1ccccc1</smiles>

58

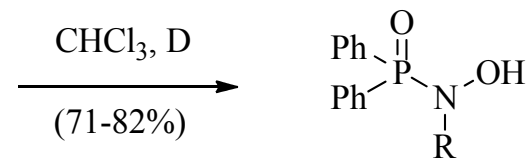

59

$$
\mathrm{R}=\mathrm{Et}, n-\mathrm{Pr}, n-\mathrm{Bu}, t-\mathrm{Bu}, n-\mathrm{Pr}_{2} \mathrm{CH}
$$

\section{Scheme 23}

2.1.2.2 Carbon-nitrogen single bond formation reactions (Scheme 16b). Easily available $N$ (diethoxyphosphoryl)benzyloxylamine $\mathbf{6 0}$ was shown to be a convenient protected substrate for regioselective $\mathrm{N}$-alkylation by means of diverse halides under basic conditions (sodium hydride/tetrabutylammonium bromide $(\mathrm{TBAB}))^{35}$ The phosphorylated compound $\mathbf{6 0}$ was prepared according to the literature procedure from $N$-benzylhydroxylamine hydrochloride and diethyl phosphonate. ${ }^{32} \mathrm{~N}$-Alkylation to $\mathbf{6 1}$ is performed using different bases for metallation, and the best yield is obtained at room temperature when sodium hydride and catalytic amounts of TBAB are used (Scheme 24).<smiles>CCOP(=O)(O)NOCc1ccccc1</smiles>

60

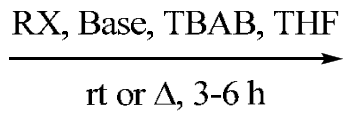

$(56-95 \%)$<smiles>[R]N(OCc1ccccc1)P(=O)(O)OCC</smiles>

61

$\mathrm{R}=\mathrm{Me}, i$ - $\mathrm{Pr}, i$-Bu, Allyl, $\left(\mathrm{CH}_{2}\right)_{3} \mathrm{Br},\left(\mathrm{CH}_{2}\right)_{4} \mathrm{Br}, \mathrm{Bn}, \mathrm{Bu}$,

$\left(\mathrm{CH}_{2}\right)_{3} \mathrm{~N}(\mathrm{OBn}) \mathrm{P}(\mathrm{O})(\mathrm{OEt})_{2},\left(\mathrm{CH}_{2}\right)_{3} \mathrm{P}(\mathrm{O})(\mathrm{OEt})_{2}$

\section{Scheme 24}

Dialkyl $\mathrm{N}$-alkoxyphosphoramidates 62 are good starting materials for the synthesis of halophosphoramides 63, which can serve as reagents for the regiospecific functionalization of terminal $\mathrm{C}-\mathrm{C}$ double bonds. ${ }^{32}$ The method of synthesis of halophosphoramides consists of the chlorination of diethyl $N$-alkoxyphosphoramidates 62 by means of gaseous chlorine at room temperature in an aqueous buffered solution containing acetic acid and sodium acetate (Scheme 25). The compounds 62 are much more reactive towards 1-alkenes than diethyl $N, N$ dichlorophosphoramidate, undergoing addition reaction to afford two regioisomers 64a and 64b in a 3:1 ratio, the anti-Markovnikoff adduct 64a being the main component of the mixture, apparently formed by a free-radical reaction. 


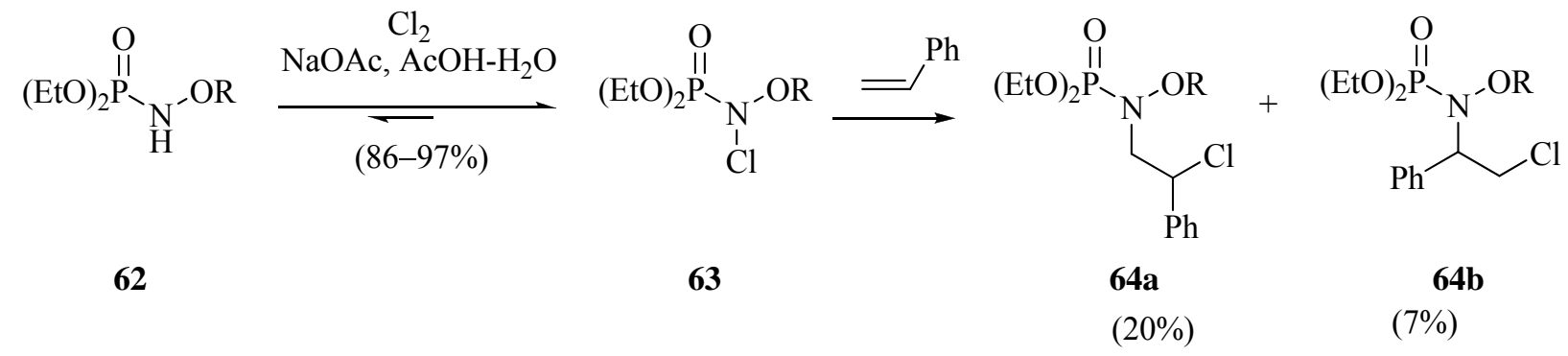

Scheme 25

\subsection{Reactivity of phosphorus substituted hydroxylamine derivatives}

\subsubsection{Phosphorus $O$-substituted hydroxylamines}

2.2.1.1 Rearrangement reactions. $N$-Alkyl-O-(diphenylphosphinyl)hydroxylamines rearrange on heating to the thermodynamically more stable $N$-phosphinylated derivatives and have been used for the preparation of $N$-alkyl- $N$-(diphenylphosphinyl)hydroxylamines (see Section 2.1.2.1.3). ${ }^{34}$ When bis- $N$-(trifluoromethyl)nitroxybis(trifluoromethyl)phosphine 23, obtained by reaction of trifluoronitrosomethane 22 with tris(trifluoromethyl)phosphine (see Section 2.1.1.1.2), is heated at $100{ }^{\circ} \mathrm{C}$ it undergoes isomerization to give the corresponding phosphine oxide 65 (Scheme 26). ${ }^{20}$<smiles>CN(C)OP(C)C(F)(F)F</smiles>

23 65

\section{Scheme 26}

Cleavage of the $\mathrm{N}-\mathrm{O}$ bond has been reported by thermal treatment of $O$-phosphoryl hydroxylamines $9\left(\mathrm{X}=\mathrm{CH}_{2}\right)$ or $\mathbf{1 0}(\mathrm{X}=\mathrm{MeN})$ obtained by reactions between enehydroxylamines and diethyl chlorophosphate (see Section 2.1.1.1.1). Subsequent rearrangement affords functionalized enaminone $\mathbf{6 6}$ or 1,2-dihydropyrimidin-4-one 67, respectively (Scheme 27). ${ }^{15}$ 

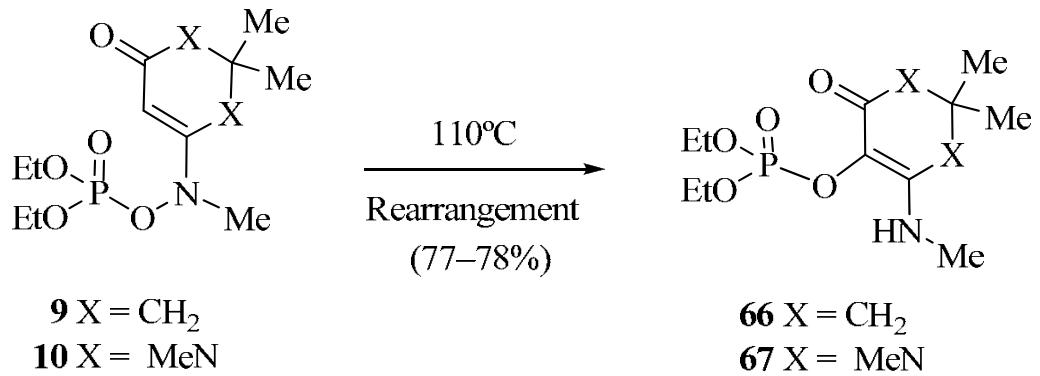

Scheme 27

However, when $N, N$-dibenzyl-O-(diphenylphosphinyl)hydroxylamine $\mathbf{6 8}$ is heated, imine $\mathbf{7 1}$ and diphenylphosphinic acid $\mathbf{7 0}$ are obtained (Scheme 28). ${ }^{24,36}$ This mode of elimination may be rationalized by a cyclic transition state 69 involving the phosphinyl group. Thermal oxidative deamination of amines is achieved by reaction with bis(diphenylphosphinyl)peroxide (see Section 2.1.1.2) without isolation of the intermediate $N, N$-disubstituted-O(diphenylphosphinyl)hydroxylamines 69, which upon heating gives regioselectively the unstable imines 71, isolated as benzaldehyde.

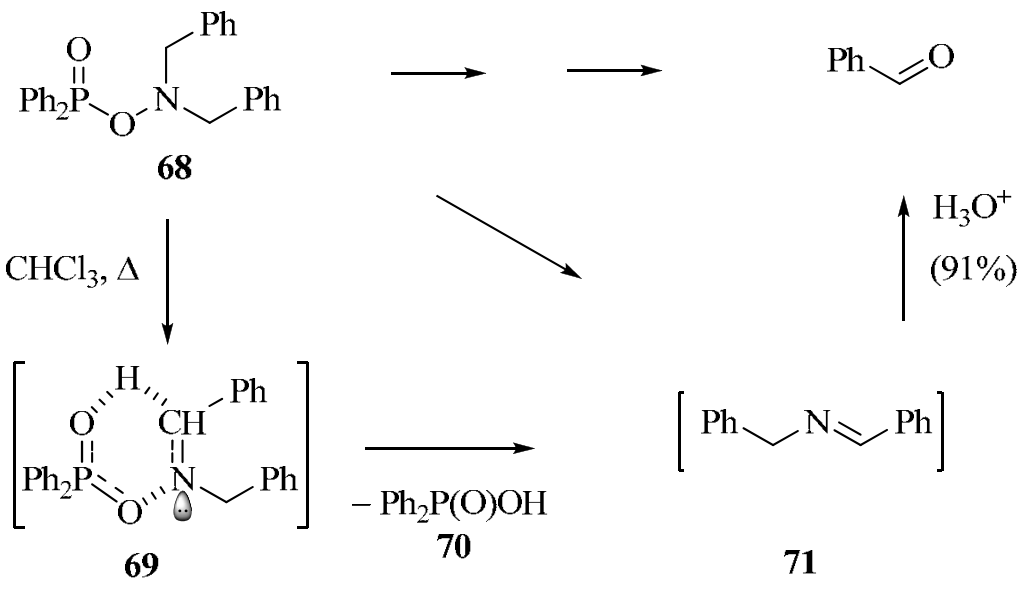

\section{Scheme 28}

2.2.1.2 Hydrolysis reactions. Acidic hydrolysis of $N$-alkyl- $\left(\mathrm{R}^{2}=\mathrm{H}\right)$ or $N, N$-dialkyl $O$ (diphenylphosphinyl)hydroxylamines $\mathbf{3}$ can afford hydroxylamines $\mathbf{2}$ in good yields by means of $\mathrm{P}-\mathrm{O}$ bond cleavage (Scheme 29). ${ }^{12 \mathrm{a}, \mathrm{b}, \mathrm{g}}$ Similarly, $N, N$-bis(trifluoromethyl)hydroxylamine $2\left(\mathrm{R}^{1}=\right.$ $\left.\mathrm{R}^{2}=\mathrm{CF}_{3}\right)$ is obtained by the hydrolysis of $N, N, P, P$-tetrakis(trifluoromethyl)-Ophosphinylhydroxylamine ${ }^{20}$ in the presence of hydrochloric acid. 


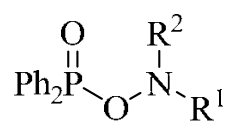

3

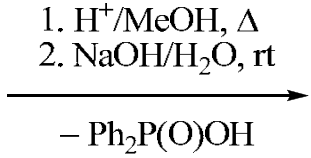

(41-96\%)
$\mathrm{HO}^{-\mathrm{R}^{2}}{ }_{-\mathrm{R}^{\mathrm{I}}}$

2

\section{Scheme 29}

Compound EM2487 72, a product isolated from Streptomyces sp. Mer-2487, has an inhibitory effect on HIV-1 replication in chronically infected cells as well as acutely infected cells. ${ }^{37}$ EM2487 is a new class of secondary metabolites of microbial origin whose structure is completely different from that of known nucleoside antibiotics. In order to elucidate the unique structure of the title compound, hydrolysis reactions were performed. Fragments 73-77 support the presence of $O$-phosphorus substituted hydroxylamine moiety in the structure of compound EM2487 (Scheme 30).

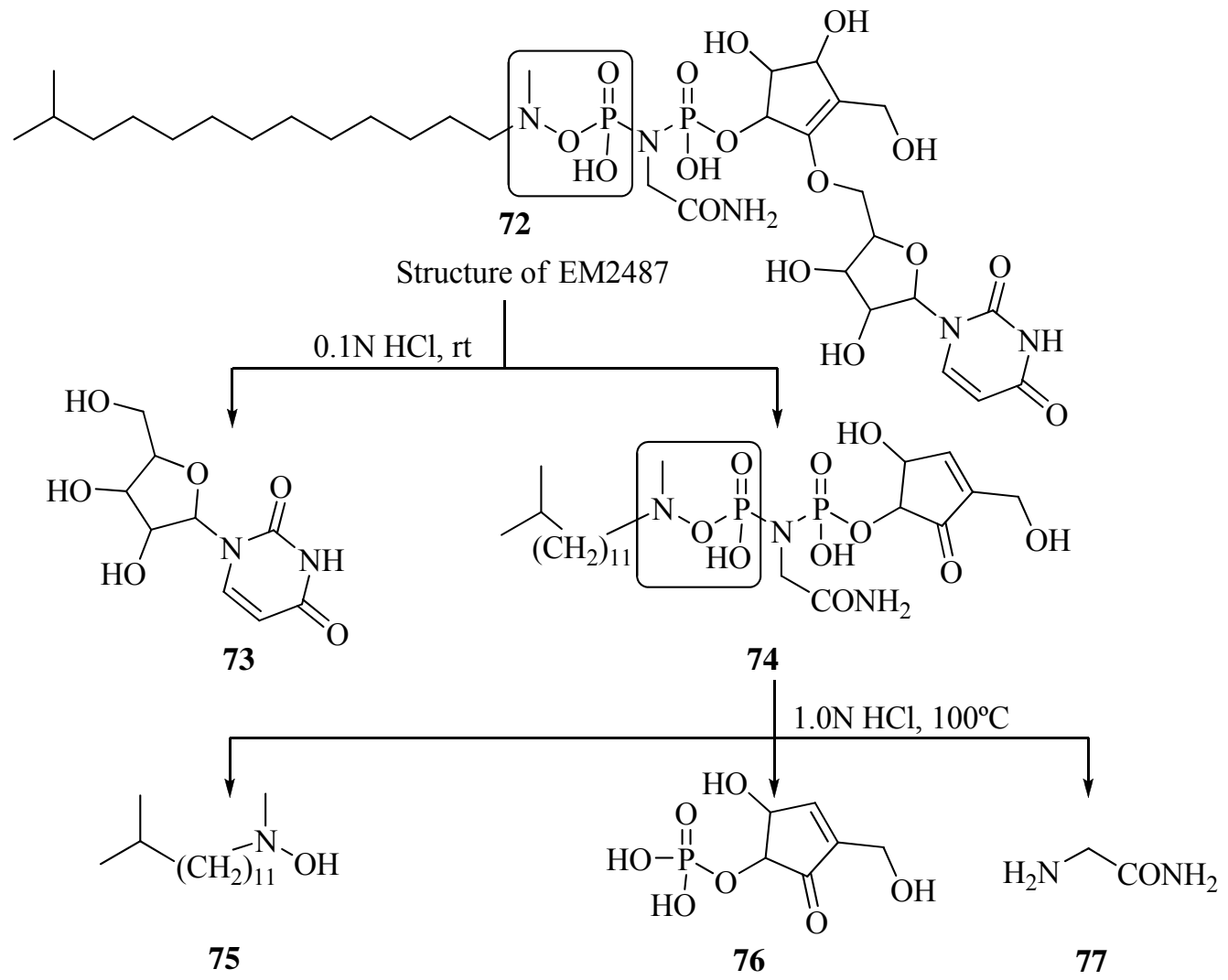

\section{Scheme 30}

On the other hand, the $[\mathrm{P}(\mathrm{O})-\mathrm{O}-\mathrm{N}]$ functionality has been rarely found in dinucleotides. ${ }^{38}$ However, a protected-O-phosphorylhydroxylamine moiety occurs in the stable hapten 79. Its 
preparation has been reported by deprotection of the cyanoethyl group of $78\left(\mathrm{Et}_{3} \mathrm{~N}\right.$ in pyridine) followed by removal of the two allyl-based protecting groups $\left[\mathrm{Pd}\left(\mathrm{PPh}_{3}\right)_{4}, \mathrm{PPh}_{3}, n\right.$ - $\mathrm{BuNH}_{2}$, and $\mathrm{HCO}_{2} \mathrm{H}$ in $\mathrm{CH}_{2} \mathrm{Cl}_{2}$ ] to give the hapten 79 as the $n$-butylammonium salt (Scheme 31 ). The order of these deprotection steps is very important since an initial cleavage of the allyl groups from $\mathbf{7 8}$ could give an unidentified mixture of compounds.

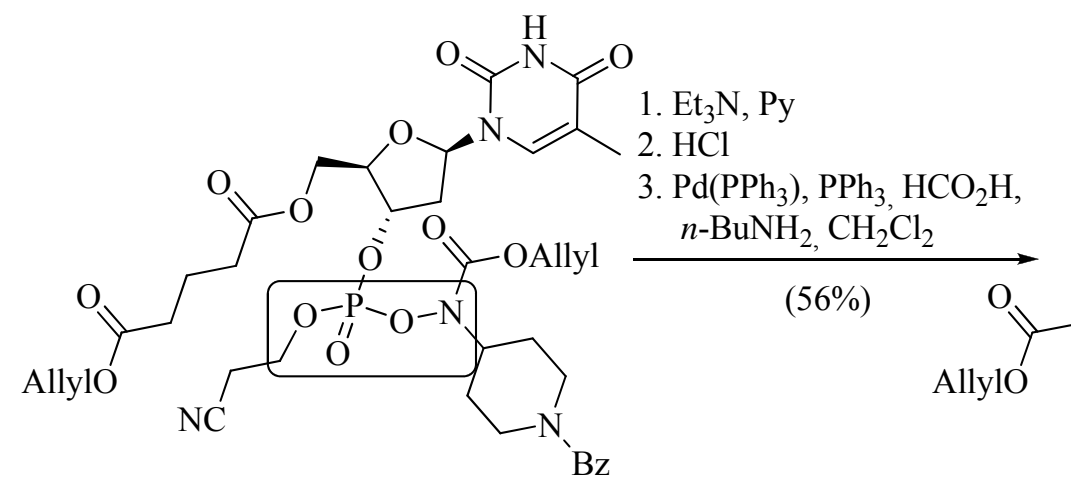

78

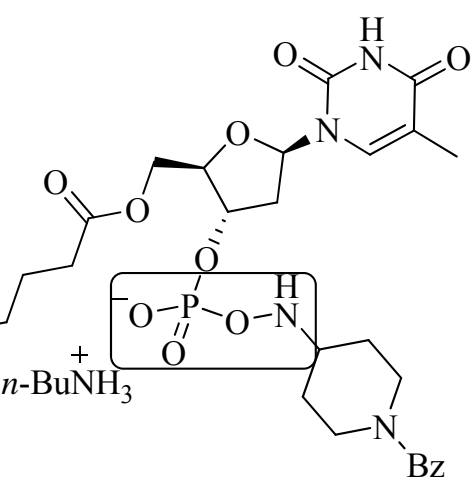

79

\section{Scheme 31}

2.2.1.3 Reduction reactions. Amino diethyl phosphate derivatives of $N$ phenylethylhydroxylamines were prepared (see Section 2.1.1.1.1) in order to determine the stereochemistry of precursors $N$-phenylethylhydroxylamines. For this purpose, lithium-ammonia reduction of diethyl phosphate derived hydroxylamines 15a,b towards $N, N$-bis $(\alpha$ phenylethyl)amines 80a,b has been accomplished and the stereochemistry of obtained compounds 80a,b determined (Scheme 32). ${ }^{17}$<smiles>[M]C(c1ccccc1)N(OP(=O)(OCC)OCC)C(C)c1ccccc1</smiles>

$(S, R)-\mathbf{1 5} \mathbf{a}$<smiles>[M]C(c1ccccc1)N(OP(=O)(OCC)OCC)[C@@H](C)c1ccccc1</smiles>

$(R, R)-\mathbf{1 5 b}$<smiles>[M]C([PH+][O-])N([Tl])C([M])c1ccccc1</smiles>
(76\%)

$(S, R)-80 \mathbf{a}$

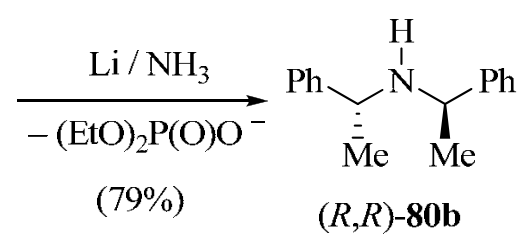

\section{Scheme 32}


2.2.1.4 Electrophilic amination. $O$-Phosphorus substituted hydroxylamines 82 have been often used as aminating reagents ${ }^{39}$ in an electrophilic amination. In this process, reaction between organometallic compounds $\mathbf{8 1}\left(\mathrm{R}^{1}=\mathrm{R}_{3} \mathrm{C}, \mathrm{R}_{2} \mathrm{~N}\right)$ and $O$-phosphorus substituted hydroxylamines 82 proceeds through carbon-nitrogen or nitrogen-nitrogen bond formation, affording the corresponding amines or hydrazines (Scheme 33).

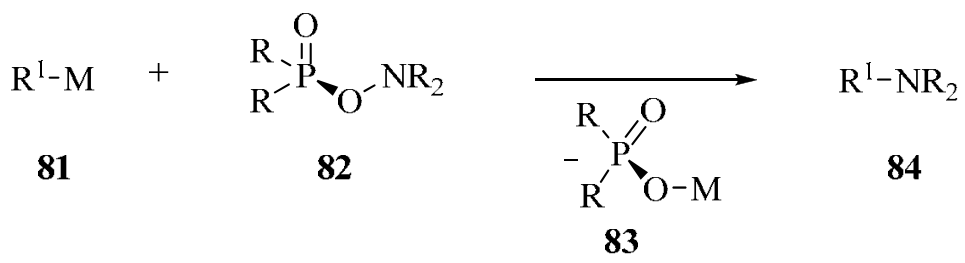

\section{Scheme 33}

When Grignard reagents derived from phenylacetylene are used with $O$-phosphinylated aminating reagents the corresponding ethinylamino (ynamine) derivatives are obtained through carbon-nitrogen bond formation reaction. ${ }^{12 \mathrm{c}}$ Likewise, the $O$-(trimethylsilyl)aldehyde cyanohydrin anions $\mathbf{8 7}$ react with $O$-phosphinylated aminating reagents $\mathbf{8 8}$ to give amines $\mathbf{8 9}$. This electrophilic amination corresponds to a mild and specific oxidation of the aldehydes $\mathbf{8 5}$ to the amides 90 via 86-89 (Scheme 34), which proceeds in basic medium. ${ }^{12 b}$

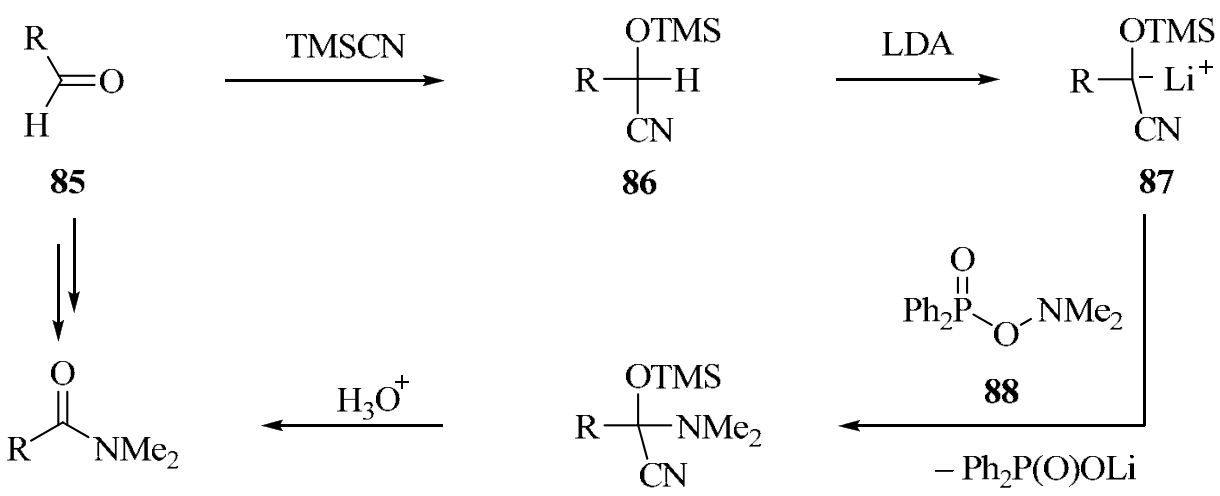

90

89

\section{Scheme 34}

By intramolecular nucleophilic substitution on the nitrogen atom, proline derivatives were prepared. ${ }^{14}$ In this case, 5 -aminovaleric acid derivatives with diphenylphosphinyloxy leaving group $^{12 \mathrm{e}, 13 \mathrm{~b}}$ (see Section 2.1.1.1.1) cyclizes in the presence of a base and pyrrolidines 91 are formed (Scheme 35). 


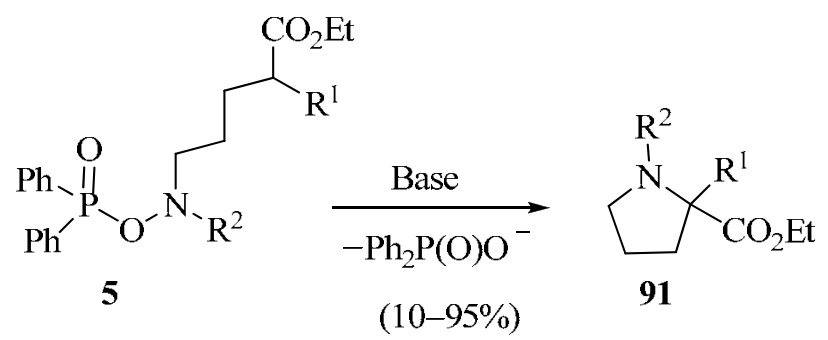

\section{Scheme 35}

O-Di(p-methoxyphenylphosphinyl)hydroxylamine 93 reacts efficiently with stabilized sodium or potassium enolates derived from malonates, phenylacetates and phenylacetonitriles 92 and it is sufficiently soluble for its use in solution at $-78{ }^{\circ} \mathrm{C}$ (Scheme 36). ${ }^{40}$ As the $\mathrm{p} K_{\mathrm{a}}$ of the substrate increases, amination yields to 94 decreases. Aminations using these reagents 93 are improved with respect to those using (diphenylphosphinyl)hydroxylamine $93(\mathrm{Ar}=\mathrm{Ph}){ }^{12 \mathrm{e}, 13 \mathrm{~b}}$

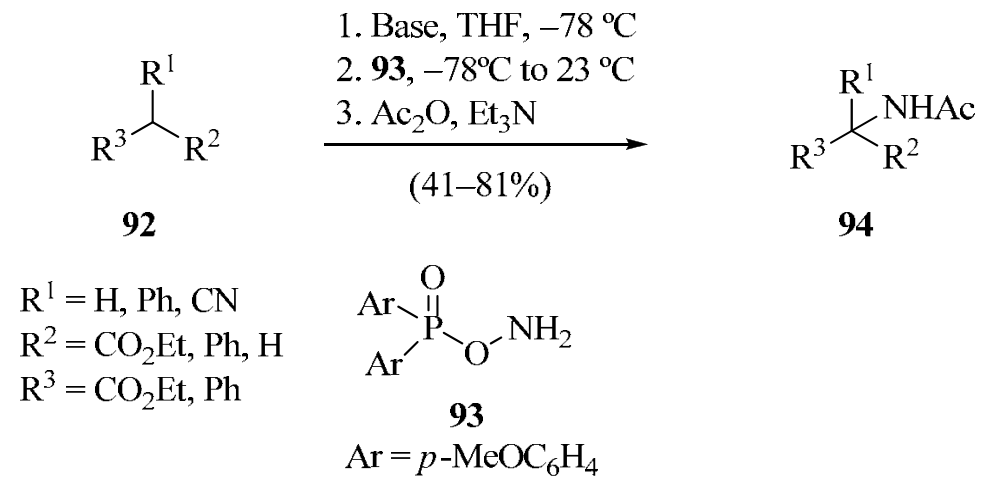

\section{Scheme 36}

Boche et al. established that nucleophilic substitution occurs at the nitrogen of the $O-(N, N-$ dimethylamino)diarylphosphinyl derivative 95. ${ }^{12 b, 16,24}$ Compound 95 converts into 96 on treatment with LDA followed by reaction with water, acidification and treatment with diazomethane (Scheme 37). 
<smiles>CNOP(=O)(c1ccccc1)c1ccccc1CC#N</smiles>

95
1. LDA

2. $\mathrm{H}_{3} \mathrm{O}^{+}$

3. $\mathrm{CH}_{2} \mathrm{~N}_{2}$<smiles>COP(=O)(c1ccccc1)c1ccccc1C(C#N)C#N</smiles>

96

\section{Scheme 37}

Transfer of nitrogen from oxygen to carbanions could take place within large endocyclic rings. ${ }^{41}$ In order to distinguish between the intermolecular and intramolecular pathways, the conversion of 97 to 99 via carbanion 98 is studied. ${ }^{13}$ The results obtained show that the reaction proceeds via a trigonal bipyramidal transition structure and that a large bond angle is required for nucleophilic displacement at nitrogen. When a ring is of sufficient size to allow both the entering and leaving groups to be simultaneously apical in a trigonal bipyramidal transition structure, an intramolecular endocyclic reaction would be expected. This study has been carried out in a prospective 16-membered ring (Scheme 38).

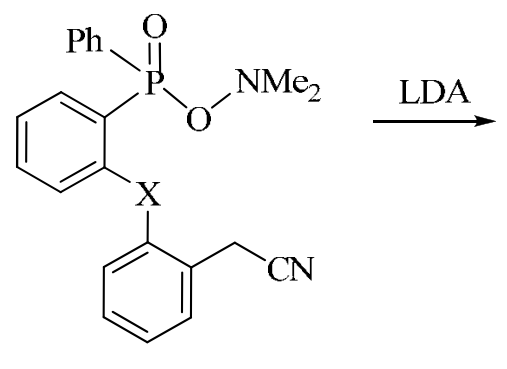

97<smiles>CNOP(=O)(c1ccccc1)c1ccccc1[X]c1ccccc1CC#N</smiles>

98

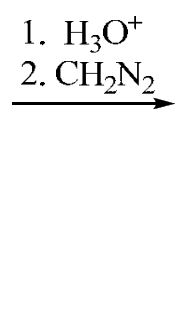

$$
\mathrm{X}=\mathrm{CH}_{2}, \curvearrowright \mathrm{O} \sim \mathrm{O}^{\prime}
$$<smiles>CNC(C#N)c1ccccc1[X]c1ccccc1P(=O)(OC)c1ccccc1</smiles>

99

\section{Scheme 38}

The chiral aminating reagents $(-)$-13a and (+)-13b have been prepared in a 'one-pot' reaction from (-)-ephedrine and (+)-ephedrine ${ }^{16}$ (see Section 2.1.1.1.1). These compounds react with carbon nucleophiles 100 to yield 101 and the optically active amines 102 with moderate conversion and up to $44 \%$ ee (Scheme 39 ). 


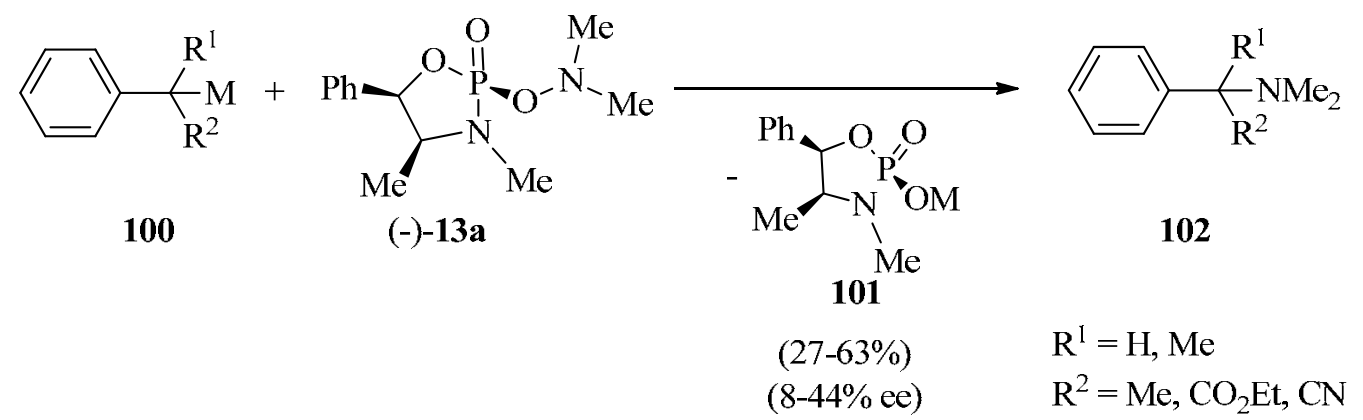

\section{Scheme 39}

Nitrogen-nitrogen bond formation can be performed by electrophilic aminating reagents as $O$-(diphenylphosphinyl)hydroxylamines. ${ }^{42}$ The reactions of the $O$ (diphenylphosphinyl)hydroxylamines 103 with the amines 104 lead to the hydrazines 105 via electrophilic amination, and to the symmetrical azo compounds $107 .{ }^{43}$ The behaviour of the acceptor substituted $O$-(diphenylphosphinyl)hydroxylamines 103 towards $N$-methylaniline $\left(\mathrm{R}^{1}=\right.$ $\mathrm{R}^{2}=n$ - $\left.\mathrm{Pr}\right)$, morpholine $\left(\mathrm{R}^{1} \mathrm{R}^{2}=\mathrm{CH}_{2} \mathrm{CH}_{2} \mathrm{OCH}_{2} \mathrm{CH}_{2}\right)$ and di-n-propyl amine $\left(\mathrm{R}^{1}=\mathrm{Me}, \mathrm{R}^{2}=\mathrm{Ph}\right)$ has been studied. It can be concluded that, the acceptor qualities of substituents increase in the order $\mathrm{COMe}<\mathrm{CN}<\mathrm{SO}_{2} \mathrm{Me}<\mathrm{NO}_{2}$ (Scheme 40). On the other hand, it was seen that there is a competition between the nucleophilic attack of the amines 104 on the electrophilic nitrogen atoms of 103 to give hydrazines 105, and a reaction starting with deprotonation which leads to symmetrical azo compounds $\mathbf{1 0 7}$ through the corresponding ammonium salts 106.

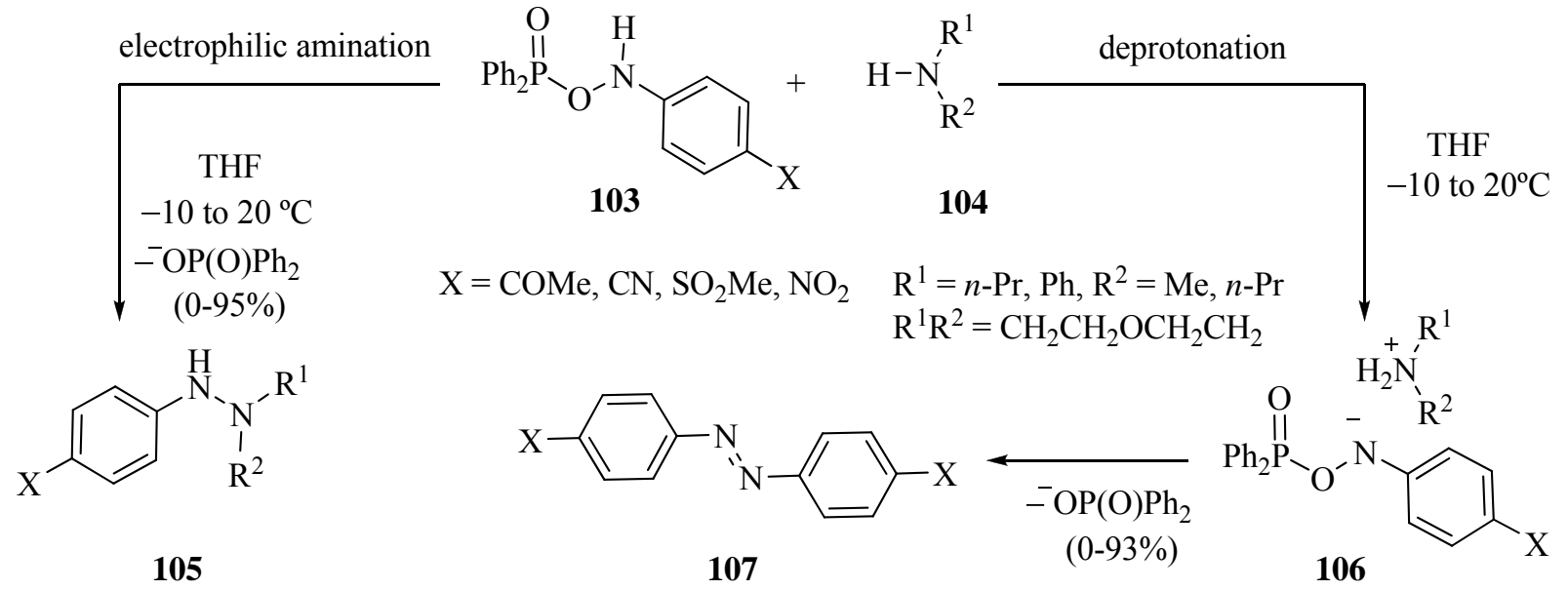

\section{Scheme 40}

2.2.1.5 Oxidation reactions. Derivatives 35 under oxidative conditions afford the corresponding phosphinic acid derivatives 110, via $\mathrm{N}$-oxide intermediate 109, or the corresponding phosphinic 
anhydride 111 by reaction of the $N$-methylhydroxylamine derivative 108 with the aromatic carboxylic acid (Scheme 41$){ }^{25}$<smiles>[R17][OH+]ON(C)[Na]</smiles>

35 $\mathrm{R}=\mathrm{NMe}_{2}, \mathrm{OEt}$

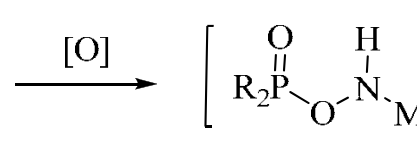

108

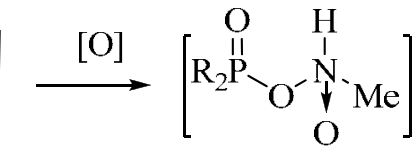
109 $\longrightarrow \mathrm{MeNO}$<smiles>O=P(O)([SnH])c1ccccc1</smiles>

110

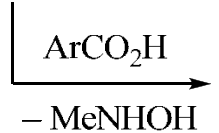<smiles>[R17][R](=O)OC(=O)[Al]</smiles>

111

\section{Scheme 41}

\subsubsection{Phosphorus $N$-substituted hydroxylamines}

2.2.2.1 Rearrangement reactions. Among studies of amine oxidation with bis(diphenylphosphinyl)peroxide, a general method for the preparation and isolation of $N$-alkyl$N$-(diphenylphosphinyl)hydroxylamines $112 \quad(\mathrm{R}=n$-Bu $) \quad$ or $\quad N$-alkyl-O(diphenylphosphinyl)hydroxylamine 115 through intermediates 113 and 114 has been reported (see Section 2.1.2.1.3). ${ }^{34}$ In methanolic solution, 115 reacts with sodium methoxide at room temperature to give nearly equal amounts of diphenylphosphinic acid derivative $\mathbf{1 1 6}$ and methyl diphenylphosphinate 118 together with imine 117 and hydroxylamine 119, by competing attack of methoxide at the O-NH moiety or at the phosphorus atom of 115, respectively (Scheme 42). Similar rearrangements have been reported previously $(\mathrm{R}=\mathrm{H}){ }^{44}$

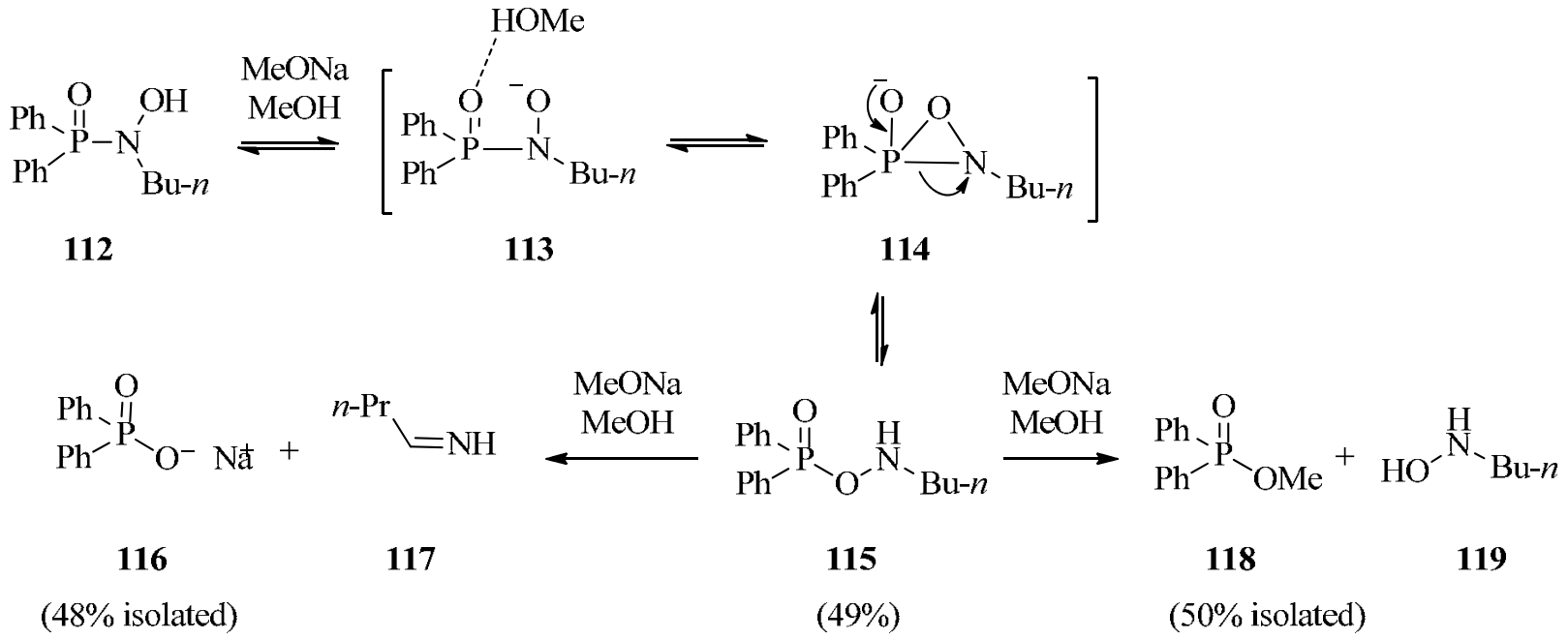

\section{Scheme 42}


2.2.2.2 Hydrolysis reactions. Taking into account the lability of the $\mathrm{P}-\mathrm{N}$ bond, dephosphorylation of $N$-substituted-O-benzylhydroxylamines 61 (see Section 2.1.2.2) has been carried out by treatment with $4 \mathrm{M} \mathrm{HCl}$ in ethanol at reflux, and the corresponding dephosphorylated compounds $\mathbf{1 2 0}$ were obtained as crystalline hydrochlorides, as oxalate hemiacetals or as free amines (Scheme 43). ${ }^{35}$ Therefore, phosphoryl groups can be regarded as convenient protecting groups for hydroxylamines.

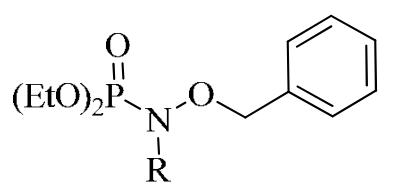

61

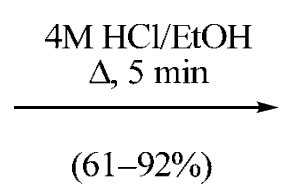

$(61-92 \%)$

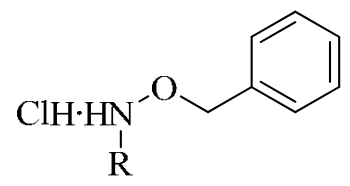

120

$\mathrm{R}=\mathrm{Me}, i-\mathrm{Pr}, i-\mathrm{Bu}, \mathrm{Allyl},\left(\mathrm{CH}_{2}\right)_{3} \mathrm{Br},\left(\mathrm{CH}_{2}\right)_{4} \mathrm{Br}, \mathrm{Bn}, \mathrm{Bu}$,

$\left(\mathrm{CH}_{2}\right)_{3} \mathrm{~N}(\mathrm{OBn}) \mathrm{P}(\mathrm{O})(\mathrm{OEt})_{2},\left(\mathrm{CH}_{2}\right)_{3} \mathrm{P}(\mathrm{O})(\mathrm{OEt})_{2}$

\section{Scheme 43}

2.2.2.3 $N$-Alkylation reactions. $N$-Phosphorylated $O$-alkylhydroxylamines are good starting materials for the synthesis of halophosphoramides, which can serve as reagents for the regiospecific functionalization of terminal $\mathrm{C}-\mathrm{C}$ double bonds, ${ }^{32}$ as has been reported by the reaction of diethyl $N$-alkoxyphosphoramidates with alkenes (see Section 2.1.2.2).

2.2.2.4 Oxidation reactions. Trifluoronitrosomethane 22 reacts with bis(trifluoromethyl) phosphine 51 to give the phosphinyl substituted hydroxylamine, $52^{45}$ probably via a $N$ phosphino-hydroxylamine followed by oxidation (see Section 2.1.2.1.2, Scheme 21). ${ }^{20}$ Similarly, previous reactions with diethyl phosphite affording hydroxamic acid derivatives have been reported. $^{46}$

2.2.2.5 Elimination reactions. $\quad[N$-Hydroxy- $N-(1$-trifluoromethylethenyl) $]$ amido diethylphosphate 49 is obtained by reaction of triethyl phosphite and 3-bromo-1,1,1trifluoropropane-2-oxime 48 (see Section 2.1.2.1.1). Compound 49 adds water in a Markovnikov manner across the $\mathrm{C}-\mathrm{C}$ double bond to form [N-hydroxy- $N$-(1-trifluoromethyl-1hydroxyethyl)]amido diethyl phosphate 121. ${ }^{33}$ Subsequently, water may be abstracted using dicyclohexylcarbodiimide (DCC) to give the corresponding N-phosphorylated 3-methyl-3trifluomethyloxaziridine 122 (Scheme 44).<smiles>C=C(N(O)P(=O)(OCC)OCC)C(F)(F)F</smiles>

49<smiles>[Y4]C([AlH2])(N(O)P(=O)(OCC)OCC)C(F)(F)F</smiles>

121

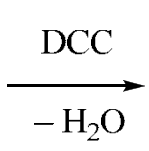

(93\%)<smiles>CCOP(=O)(OCC)N1OC1(C)C(F)(F)F</smiles>

122

\section{Scheme 44}


Addition of nitrosoalkanes to $\mathrm{O}$-silylated phosphites furnished colourless $\mathrm{N}$ trimethylsiloxyamidophosphates (see Section 2.1.2.1.2). ${ }^{33 \mathrm{~b}} \mathrm{~N}$-Phosphorylated-Osilylhydroxylamines 123, prepared by addition of nitrosotrifluoromethane to $O$-silylated phosphites, such as $(\mathrm{EtO})_{2} \mathrm{POSiMe}_{3}$, or to phosphines, as $\left(\mathrm{Me}_{3} \mathrm{SiO}\right)_{3} \mathrm{P}$, lead to the formation of $N$ phosphorus substituted imines 124 by fluorine elimination (Scheme 45).

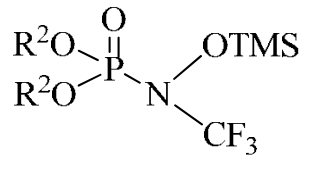

123

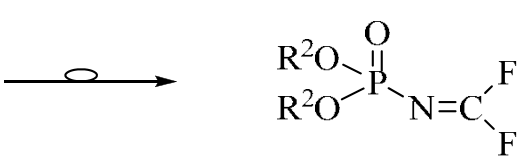

124

\section{Scheme 45}

\section{Synthesis and Reactivity of Phosphorus Substituted Hydroxamic Acid Derivatives}

Few reports have been found in the literature mentioning the combination of the phosphonic and hydroxamic functions in one molecule. We illustrate here several aspects of the synthesis and the reactivity of phosphorus $O$-substituted (III) and $N$-substituted (IV) hydroxamic acid derivatives. The phosphorus $C$-substituted derivatives $(\mathbf{V})$ are also included due to their structural similarity (Figure 2).

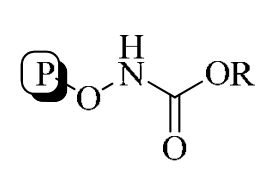

III<smiles>[R]OC(=O)n1cccc1</smiles>

IV

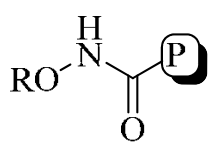

$\mathbf{V}$

$$
\text { P) }=\mathrm{POR}_{2}, \mathrm{P}(\mathrm{O})(\mathrm{OR})_{2}
$$

\section{Figure 2}

\subsection{Phosphorus $O$-substituted hydroxamic acid derivatives}

The most common approaches to synthesize phosphorus substituted hydroxamic acids comprise the phosphorus-oxygen single bond formation between the corresponding hydroxamic acid derivatives and phosphorylated halides.

$O$-Phosphoryl hydroxamates can be prepared by $\mathrm{P}-\mathrm{O}$ bond formation reaction between the corresponding hydroxamic acid derivatives and phosphorylated halides. The synthesis of intermediate $O$-phosphodichloridate $\mathbf{1 2 6}$ is performed in situ from $N$-hydroxyurethane 125 and 
phosphorus oxychloride (Scheme 46). ${ }^{47}$ O-Phosphodichloridate 126 is an appropriate substrate for the synthesis of bis(aziridinyl)phosphinyl- $N$-hydroxyurethane derivatives 127, useful as antineoplastic agents.

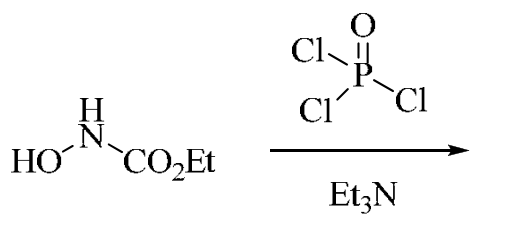

125

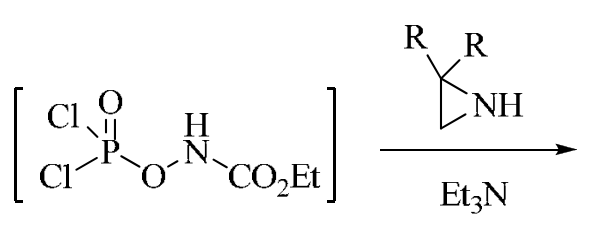

126
$(35-56 \%)$<smiles>[R]C1CN1P(=O)(ONC(=O)OCC)N1CC1([R])[R]</smiles>

127

\section{Scheme 46}

Phosphorus substituted compounds derived from hydroxamic acid are prepared by dropwise addition of diphenylphosphinyl chloride 1 to stoichiometric amounts of the hydroxamic acid 128 and triethylamine (Scheme 47). ${ }^{48}$ Some $O$-diphenylphosphinyl derivatives $129(\mathrm{R}=\mathrm{Ph}, \mathrm{Bn})$ have been tested as potential inhibitors of neuropathy target esterase, although little activity of these compounds is observed against studied targets. O-(Diphenylphosphinyl)hydroxamate $129(\mathrm{R}=t$ $\mathrm{Bu})$, whose X-ray structure has been reported, ${ }^{49}$ can be applied as electrophilic aminating agent, ${ }^{34,50-52}$ or in Schmidt reactions. ${ }^{43}$

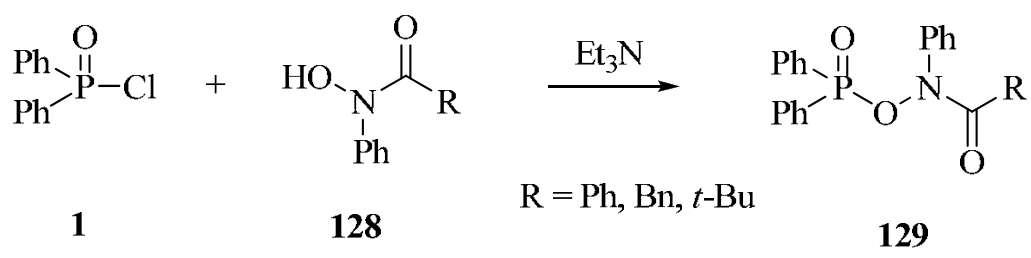

\section{Scheme 47}

The reaction between $N$-methylbenzohydroxamic acid and various chlorides of tervalent phosphorous has been studied. ${ }^{53} N$-Methyl-p-(methylphenyl)hydroxamic acid 130 reacts rapidly with phosphorus compounds XYPCl $131\left(\mathrm{X}=\mathrm{Ph}, \mathrm{Y}=\mathrm{OEt}\right.$ and $\left.\mathrm{XY}=\mathrm{OCH}_{2} \mathrm{CH}_{2} \mathrm{O}\right)$ in the presence of pyridine to give P(III) intermediates 132 (Scheme 48). They decompose at room temperature with homolysis of the $\mathrm{N}-\mathrm{O}$ bond to give isomeric $N$-phosphine oxides 134, accompanied by varying amounts of $O$-hydroxamic acids 135, $N$-methyl-4-methylbenzamide 133, and phosphoryl-radical related products. The origin of $O$-phosphinylhydroxamic acids 135 is not known, but presumably involves the combination of phosphinyl and acylnitroxyl radicals. 
Compounds 137 are also synthesized by treatment of hydroxamic acid 130 with the appropriate chlorophosphine oxide 136 in the presence of one equivalent of base (Scheme 48).

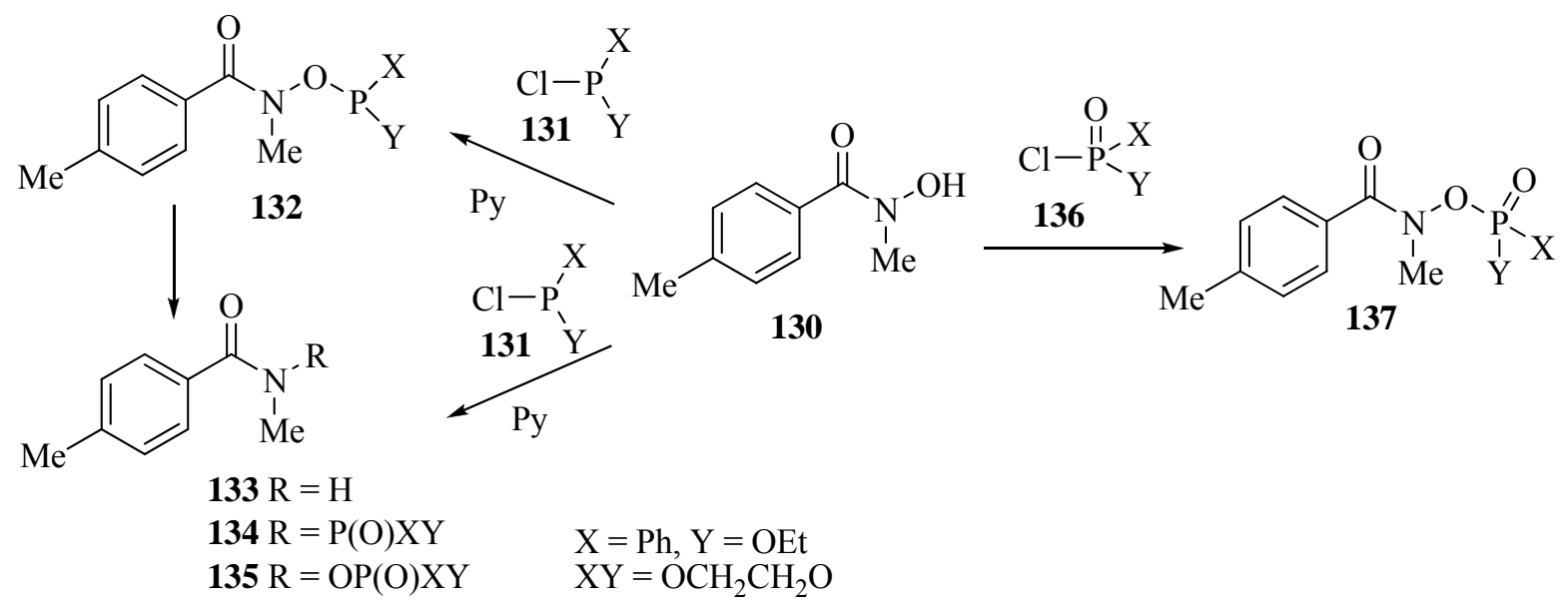

\section{Scheme 48}

The synthesis of a new class of aryl adenylate analogs with potent inhibitory activity against enterobactin biosynthesis enzyme (EntE), an enzyme that catalyzes the synthesis of 2,3dihydrobenzoyl adenylate (DHB-AMP) during the early stages of enterobactin biosynthesis, has been reported. ${ }^{54}$ The authors design a stable mimic of DBH-AMP as a potential inhibitor, which contains an $\mathrm{N}$-acyl hydroxamoylphosphate group in place of the labile carboxylic-phosphoric anhydride linkage. Compounds 140 are obtained by combining hydroxamic acids 138 with imidazole-activated adenosine 5'-phosphate (AMP-Im) 139 (Scheme 49).
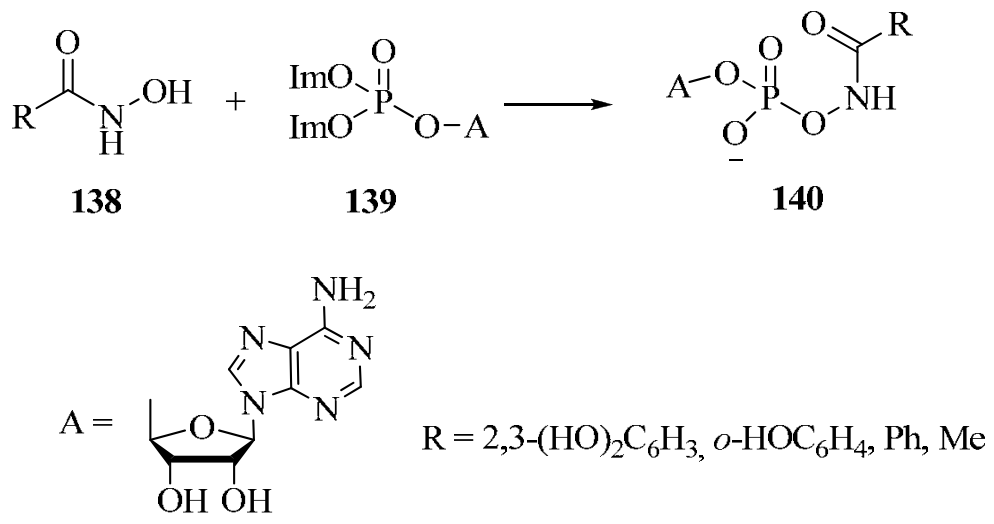

\section{Scheme 49}

O-Phosphorus substituted hydroxamates can also be prepared by $\mathrm{P}-\mathrm{O}$ bond formation reaction between the corresponding hydroxamic acid derivatives and phosphorus derivatives as phosphonates or phosphinothioyloxy disulfanes. Direct thionation of hydroxamic acids with Lawesson's reagent (LR) 142 can be very useful in the synthesis of thio analogues of natural 
hydroxamates and $N$-hydroxythiopeptides. ${ }^{55,56}$ Treatment of hydroxamic acids with LR gives a mixture of different phosphorus-containing products, such as $O$-thiophosphonylated $146(\mathrm{R}=\mathrm{H})$, pyrothiophosphonate $145(\mathrm{R}=\mathrm{H})$, and (4-methoxyphenyl)phosphothioic acid $144(\mathrm{R}=\mathrm{H}$, Scheme 50). The formation of these compounds 144-146 is explained by the electrophilic attack of metadithiophosphonate 142 (AnPSS) on the oxygen atom of the hydroxy group in the hydroxamic acid 141 to give the primary intermediate $O$-dithiophosphonylated hydroxamic thioacid 143 (detected by ${ }^{31} \mathrm{P} N \mathrm{NM}$ ). To confirm the formation of compound 146 the reaction mixture is treated with TBDMSCl in the presence of triethylamine, or with diazomethane or methyl iodide in the presence of triethylamine, and compound $\mathbf{1 4 6}$ is transformed in situ to a mixture of $O$ - and $S$-methyl esters. ${ }^{55}$

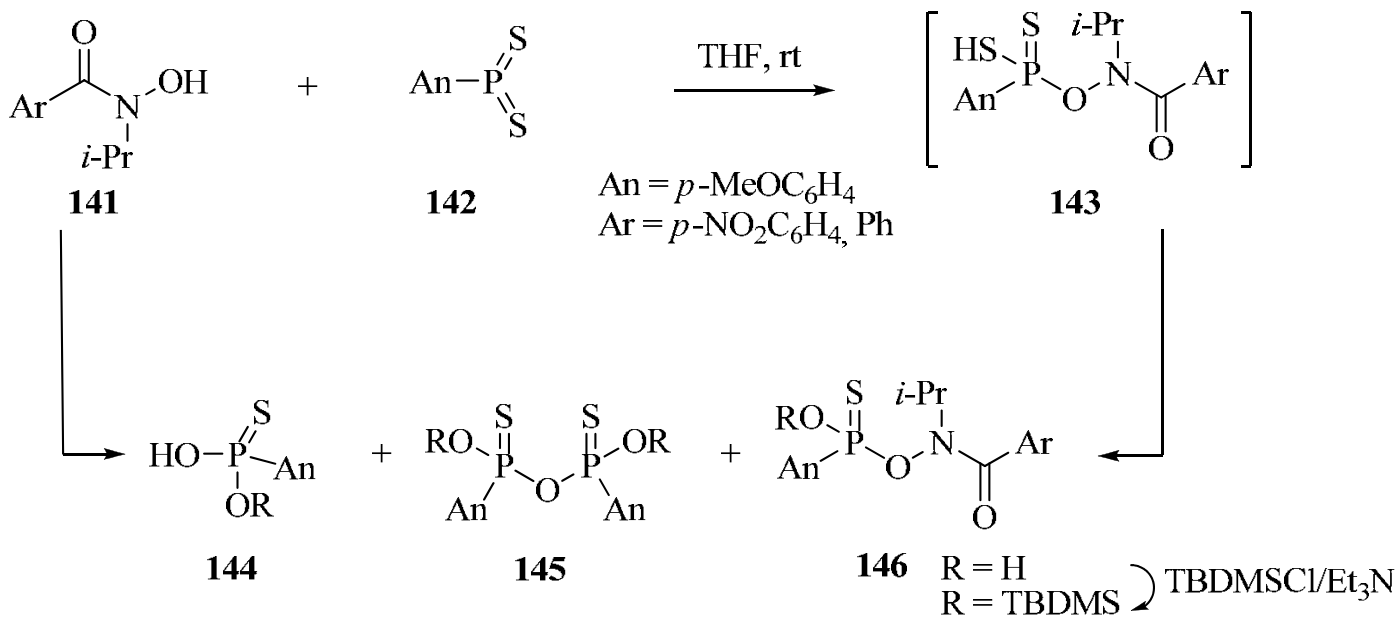

\section{Scheme 50}

Reaction of various disulfanes 147 with $N$-alkylbenzohydroxamates 148 has been investigated (Scheme 51). ${ }^{57}$ Disulfanes 147 are treated with benzohydroxamate salts 148 to give $O$-phosphothioylated hydroxamic acids 149 (Scheme 51). The reaction has also been studied using optically pure disulfane. X-Ray analysis shows that the product is formed with a complete inversion of configuration. Therefore, the reaction has an ionic character and proceeds via an $\mathrm{S}_{\mathrm{N}} 2 \mathrm{P}$ mechanism at the phosphorus atom.<smiles>[R][R]([R])(=S)SSP([R])([R])=S</smiles>

147<smiles>[Y]C(=O)N([Y])O[Na]</smiles>

148

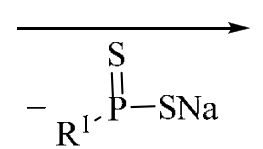

$\mathrm{Ar}=p-\mathrm{ClC}_{6} \mathrm{H}_{4}$

$\mathrm{R}^{3}=\mathrm{Me}, i-\mathrm{Pr}, t-\mathrm{Bu}$

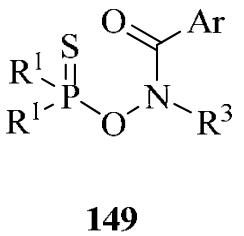

149

\section{Scheme 51}


$N$-Functionalization of phosphinylhydroxylamines can be achieved when $O$ (diarylphosphinyl)hydroxylamines 150 react with acetic anhydride to give the corresponding $N$-acetyl derivatives 151 (Scheme 52). ${ }^{12 f, 50}$

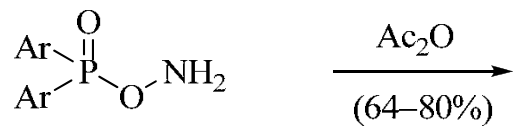

150<smiles>CC(=O)NOP(=O)([Al])[Al]</smiles>

151

\section{Scheme 52}

$\mathrm{N}$-Acyl phosphoramides have been reported to be quite nucleophilic at nitrogen in the Mitsunobu reaction. Intramolecular nucleophilic transfer reaction by treatment of $N$-benzyl phosphoramide 154 with two equivalents of DIEA in acetonitrile resulted in only a small amount $(5 \%)$ of desired product 155 (Scheme 53) ${ }^{58}$ and purification was difficult due to the highly polar nature of product. However, by changing to the more electron withdrawing phenyl groups of compound $154(\mathrm{R}=\mathrm{Ph})$ (Scheme 53), the acidification of the $\mathrm{N}-\mathrm{H}$ bond of the $N$-acyl phosphoramide is possible allowing a more effective nucleophile transfer reaction to afford compound 156 in 33\% yield.

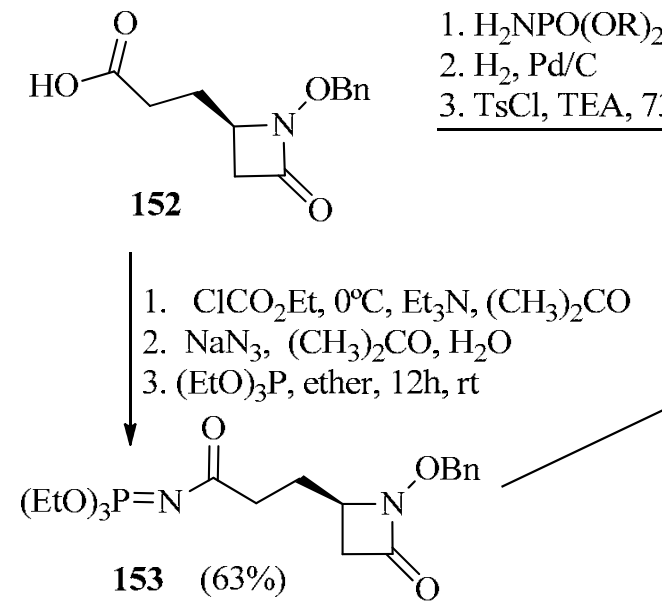

1. $\mathrm{H}_{2} \mathrm{NPO}(\mathrm{OR})_{2}$, EDC.HCl, DMAP, $\mathrm{CH}_{2} \mathrm{Cl}_{2}, 61 \%$

2. $\mathrm{H}_{2}, \mathrm{Pd} / \mathrm{C}$

3. TsCl, TEA, 73\%

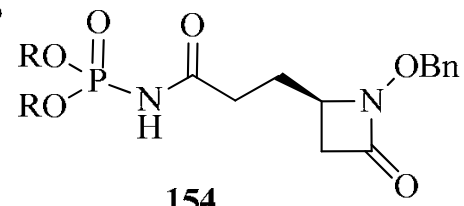

154

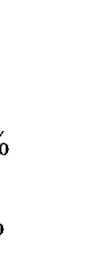

1. $\mathrm{HCl}, \mathrm{THF}, 86 \%$

2. $\mathrm{H}_{2}, \mathrm{Pd} / \mathrm{C}$

3. $\mathrm{TsCl}, \mathrm{TEA}, 55 \%$

$155 \mathrm{R}=\mathrm{Et}(5 \%)$

$156 \mathrm{R}=\mathrm{Ph}(33 \%)$

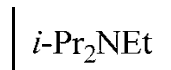

$\mathrm{CH}_{3} \mathrm{CN}$

$\mathrm{O}$

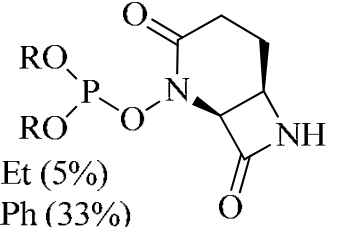

\section{Scheme 53}

\subsection{Phosphorus $\boldsymbol{N}$-substituted hydroxamic acid derivatives}

Few examples of $N$-phosphoramidate hydroxamic acid derivatives have been reported, one of them being the synthesis of new "dual antagonists" in which the 2,2-dimethylaziridine phosphinyl function is linked to the $\mathrm{N}$-hydroxyurethane rather than to the urethane moiety. ${ }^{59} \mathrm{O}$ - 
Benzyl- $N$-hydrourethane $\mathbf{1 5 7}$ is used as the starting material and reacts with phosphorus oxychloride to give the corresponding compound 158 by $\mathrm{P}-\mathrm{N}$ bond formation. Subsequent reaction with 2,2-dimethylaziridine gives $O$-benzyl- $N$-phosphinyl derivative 159 (Scheme 54).<smiles>CCOC(=O)NOCc1ccccc1</smiles><smiles>[R][R]([R])(=O)N(OCc1ccccc1)C(=O)OCC</smiles>

157

$(74 \%)$

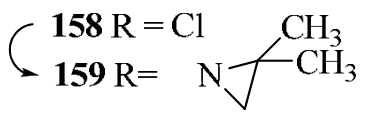

\section{Scheme 54}

\subsection{Phosphorus $C$-substituted hydroxamic acid derivatives}

Phosphonates have also been shown to exhibit biological activity in various areas by virtue of their analogy to naturally occurring phosphates and carboxylic acids. NHydroxyphosphonoformamide $161\left(\mathrm{R}^{3}=\mathrm{R}^{4}=\mathrm{H}\right)$ can be prepared from bis(trimethylsilyl) [(methylthio)carbonyl]phosphonate $\mathbf{1 6 0}\left(\mathrm{R}^{1}=\right.$ OTMS, $\left.\mathrm{R}^{2}=\mathrm{Me}\right)\left(\right.$ Scheme 55). ${ }^{60,61}$ The hydroxamic acid derivative $\mathbf{1 6 1}\left(\mathrm{R}^{1}=\mathrm{ONa}\right)$ is formed by adding a solution of $O$ (trimethylsilyl)hydroxylamine to a solution of phosphonate $\mathbf{1 6 0}$ in ethyl ether. The authors report this compound as an inhibitor of recombinant HIV-1 RT P-66 from the yeast, Saccharomyces cerevisiae $^{60}$ and as a powerful binding inhibitor of enolase. ${ }^{62}$ Analogously, several (phosphonoformyl)hydroxamates $161\left(\mathrm{R}^{1}=i-\mathrm{Pr}\right)$ can be prepared. In these cases, thioester $\mathbf{1 6 0}$ is allowed to react with hydroxylamine and its $N$-methyl and $O$-methyl derivatives in the presence of pyridine and triethylamine. ${ }^{63}$ The derivative obtained by reaction with hydroxylamine $\left(\mathrm{R}^{3}=\right.$ $\mathrm{R}^{4}=\mathrm{H}$ ) suffers Lossen rearrangement ${ }^{64}$ which involves the cleavage of the carbon-phosphorus bond in order to make a new phosphorus-nitrogen single bond of derivative 162, whose hydrolysis yields the corresponding compound 163 (Scheme 55).
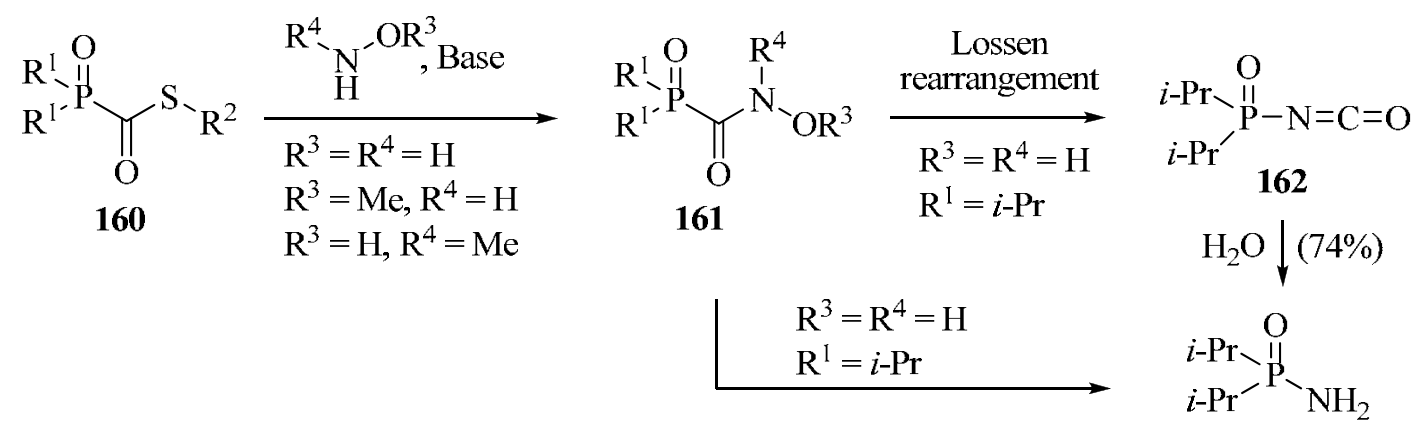

163

\section{Scheme 55}


In summary, this review presents the literature concerning the synthesis and reactivity of phosphorus substituted hydroxylamine and hydroxamic acid derivatives. It is noteworthy that not much examples regarding this type of compounds have been published, however, it is hoped that it will further stimulate the use of these compounds as versatile building blocks for the synthesis of acyclic and heterocyclic compounds which may have industrial, biological or pharmacological interest.

\section{Acknowledgements}

The present work was financially supported by the Dirección General de Investigación del Ministerio de Ciencia e Innovación (DGI, CTQ2009-12156 BQU), Universidad del País Vasco (UPV/EHU) (GIU 09/57) and Departamento de Educación, Universidades e Investigación del Gobierno Vasco (GV/EJ, IT-422-10). J. Vicario thanks the Ministerio de Ciencia e Innovación (Madrid) for a Ramón y Cajal contract.

\section{References}

1. Rappoport Z.; J. F. Liebman The Chemistry of Hydroxylamines, Oximes and Hydroxamic Acids, John Wiley \& Sons, Chichester, 2008.

2. Khlestkin, V. K.; Mazhukin, D. G. Curr. Org. Chem. 2003, 7, 967.

3. Miller, M. J.; Roosenberg, J. M.; Lin, Y.-M.; Lu, Y. Curr. Med. Chem. 2000, 7, 159.

4. (a) Brooks, C. D. W.; Summers, J. B. J. Med. Chem. 1996, 39, 2629. (b) Musser, J. H.; Kreft, A. F. J. Med. Chem. 1992, 35, 2501. (c) Stewart, A. O.; Bhatia, P. A.; Martin, J. G.; Summers, J. B.; Rodriques, K. E.; Martin, M. B.; Holms, J. H.; Moore, J. L.; Craig, R. A.; Kolasa, T.; Ratajczyk, J. D.; Mazdiyasni, H.; Kerdesky, A. J.; DeNinno, S. L.; Maki, R. G.; Bouska, J. B.; Young, P. R.; Lanni, C.; Bell, R. L.; Carter G. W.; Brooks, C. D. W. J. Med. Chem. 1997, 40, 1955.

5. (a) Kamiya, T.; Hemmi, K.; Takeno; H.; Hashimoto, M. Chem. Pharm. Bull. 1982, 30, 111.

(b) Kuzuyama, T.; Shimizu, T.; Takahashi S.; Seto, H. Tetrahedron Lett. 1998, 39, 7913.

(c) Fellermeier, M.; Kis, K.; Sagner, S.; Maier, U.; Bacher A.; Zenk, M. H. Tetrahedron Lett. 1999, 40, 2743.

6. Sawa, M.; Kiyoi, T.; Kurokawa, K.; Kumihara, H.; Yamamoto, M.; Miyasaka, T.; Ito, Y.; Hirayama, R.; Inoue, T.; Kirii, Y.; Nishiwaki, E.; Ohmoto, H.; Maeda, Y.; Ishibushi, E.; Inoue, Y.; Yoshino, K.; Kondo, H. J. J. Med. Chem. 2002, 45, 919.

7. (a) Schwartz, M. A.; Van Wart, H. E. Prog. Med. Chem. 1992, 29, 271. (b) Morphy, J. R.; Beeley, N. R. A.; Boyce, B. A.; Leonard, J.; Mason, B.; Millican, A.; Millar, K.; O’Connel; J. P.; Porter, J. Bioorg. Med. Chem. Lett. 1994, 4, 2747. 
8. Ohemeng, K. A.; Appolina, M. A.; Nguyen, V. N.; Schwender, C. F.; Singer, M.; Steber, M.; Ansell, J.; Argentieri, D.; Hageman, W. J. Med. Chem. 1994, 37, 3663.

9. For review see: Palacios, F.; Alonso, C.; de los Santos, J. M. Chem. Rev. 2005, 105, 899. Also, see: (a) de los Santos, J. M.; Ignacio, R.; Aparicio, D.; Palacios, F.; Ezpeleta, J. M. J. Org. Chem. 2009, 74, 3444. (b) de los Santos, J. M.; Ignacio, R.; Aparicio, D.; Palacios, F. J. Org. Chem. 2007, 72, 5202. (c) Palacios, F.; Aparicio, D.; de los Santos, J. M.; Rodriguez, E. Tetrahedron 1998, 54, 599. (d) Palacios, F.; Aparicio, D.; de los Santos, J. M.; Rodriguez, E. Tetrahedron Lett. 1996, 37, 1289.

10. (a) Palacios, F.; Ochoa de Retana, A. M.; Gil, J. I. Tetrahedron Lett. 2000, 41, 5363. (b) Palacios, F.; Ochoa de Retana, A. M.; Gil, J. I.; Ezpeleta, J. M. J. Org. Chem. 2000, 65, 3213. (c) Palacios, F.; Ochoa de Retana, A. M.; Alonso, J. M. J. Org. Chem. 2006, 71, 6141. (d) Palacios, F.; Ochoa de Retana, A. M.; Gil, J. I.; Alonso, J. M. Tetrahedron 2004, 60, 8947.

11. (a) Palacios, F.; Ochoa de Retana, A. M.; Alonso, J. M.; López de Munain, R. Tetrahedron: Asymmetry 2003, 24, 689. (b) Palacios, F.; Ochoa de Retana, A. M.; Gil, J. I.; Alonso, J. M. Tetrahedron: Asymmetry 2002, 2541. (c) Palacios, F.; Aparicio, D.; Ochoa de Retana, A. M.; de los Santos, J. M.; Gil, J. I.; Alonso, J. M. J. Org. Chem. 2002, 67, 7253. (d) Palacios, F.; Ochoa de Retana, A. M.; Gil, J. I.; López de Munain, R. Org. Lett. 2002, 4, 2405.

12. (a) Bernheim M; Boche, G. Angew. Chem., Int. Ed. Engl. 1980, 19, 1010. (b) Boche, G.; Bosold, F.; Nießner, M. Tetrahedron Lett. 1982, 23, 3255. (c) Boche, G.; Bernheim, M.; Nießner, M. Angew. Chem., Int. Ed. Engl. 1983, 22, 53. (d) Stahl, K.; Boche, G.; Massa, W. J. Organomet. Chem. 1984, 227, 113. (e) Boche, G.; Bernheim, M.; Schrott, W. Tetrahedron Lett. 1982, 23, 5399. (f) Harger, M. J. P. J. Chem. Soc., Chem. Commun. 1979, 768. (g) Klötzer, W.; Baldinger, H.; Karpitschka, E. M.; Knoflach, J. Synthesis 1982, 592.

13. Beak, P.; Li, J. J. Am. Chem. Soc. 1991, 113, 2796. For the use of the phosphinyl function to activate oxygen as a leaving group from nitrogen, see: (a) Reference Error! Bookmark not defined.e. (b) Colvin, E. W.; Kirby, G. W.; Wilson, A. C. Tetrahedron Lett. 1982, 23, 3835. (c) Ulbrich, R.; Famulok, M.; Bosold, F.; Boche, G. Tetrahedron Lett. 1990, 31, 1689.

14. Sheradsky, T.; Yusupova, L. Tetrahedron Lett. 1995, 36, 7701.

15. Reis, L. V.; Lobo, A. M.; Prabhakar, S.; Duarte, M. P. Eur. J. Org. Chem. 2003, 190.

16. Boche, G.; Schrott, W. Tetrahedron Lett. 1982, 23, 5403.

17. Chang, Z. Y.; Coates, R. M. J. Org. Chem. 1990, 55, 3464.

18. Reese, C. B.; Shek, L. H. K.; Zhao, Z. J. Chem. Soc., Chem Commun. 1994, 385.

19. Domingos, J. B.; Longhinotti, E.; Brandao, T. A. S.; Bunton, C. A.; Santos, L. S.; Eberlin, M. N.; Nome, F. J. Org. Chem. 2004, 69, 6024.

20. Ang, H. G.; So, K. K. J. Fluorine Chem. 1985, 27, 451. 
21. (a) Ang, H. G.; So, K. K. J. Fluorine Chem. 1985, 27, 411. (b) Ang, H. G.; So, K. K. J. Fluorine Chem. 1983, 22, 95.

22. El Nigumi, P. O.; Emeleus, H. J. J. Inorg. Nucl. Chem. 1970, 2, 3213.

23. (a) Ang, H. G.; So, K. K. J. Fluorine Chem. 1982, 21, 221. (b) Ang, H. G.; Ho, K. F. J. Fluorine Chem. 1976, 8, 497. (c) Wang, C. S. C.; Shreeve, J. M. Inorg. Chem. 1973, $2,81$. (d) Ang, H. G.; Ho, K. F. J. Organomet. Chem. 1971, 27, 349. (e) Ang, H. G.; Ho, K. F. J. Organomet. Chem. 1969, 19, 19.

24. Boche, G.; Sommerlade, R. H. Tetrahedron 1986, 42, 2703.

25. Holden, I.; Segall, Y.; Kimmel, E. C.; Casida, J. E. Tetrahedron Lett. 1982, 23, 5107.

26. Quin, L. D.; Szewczyk, J.; Szewczyk, K. M.; McPhail, A. T. J. Org. Chem. 1986, 51, 3341.

27. Burgada, R.; Mohri, A. Phosphorus and Sulfur 1981, 9, 285.

28. Goya, A. E.; Rosario, M. D.; Gilje, J. W. Inorg. Chem. 1969, 8, 725.

29. Hung, A.; Gilje, J. W. J. Chem. Soc., Chem. Commun. 1972, 662.

30. Wadsworth, W. S.; Emmons, W. D. J. Org. Chem. 1964, 29, 2816.

31. Cates, L. A. J. Med. Chem. 1968, 11, 382.

32. Zwierzak, A.; Brylikowska, J. Synthesis 1975, 712.

33. (a) Hund, H.; Röschenthaler, G.-V. Phosphorus, Sulfur \& Silicon 1996, 119, 87. (b) Hund, H.; Röschenthaler, G.-V. Phosphorus, Sulfur \& Silicon 1993, 75, 209.

34. Masse, G.; Sturtz, G. Synthesis 1988, 904.

35. Blazewska, K.; Gajda, T. Tetrahedron 2003, 59, 10249.

36. Yaouanc, J. J.; Masse, G.; Sturtz, G. Synthesis 1985, 807.

37. Takeuchi, H.; Asai, N.; Tanabe, K.; Kozaki, T.; Fujita, M.; Sakai, T.; Okuda, A.; Naruse, N.; Yamamoto, S.; Sameshima, T.; Heida, N.; Dobashi, K.; Baba, M. J. Antibiotics 1999, 52, 971.

38. Sakurai, M.; Wirsching, P.; Janda, K. D. Bioorg. Med. Chem. Lett. 1996, 6, 1055.

39. Erdik, E. Tetrahedron 2004, 60, 8747.

40. Smulik, J. A.; Vedejs, E. Org. Lett. 2003, 5, 4187.

41. Beak, P.; Basu, K. C.; Li, J. J. J. Org. Chem. 1999, 64, 5218.

42. Boche, G.; Sommerlade, R. H.; Bosold, F. Angew. Chem., Int. Ed. Engl. 1986, 25, 562.

43. Boche, G.; Meier, C.; Kleemiß, W. Tetrahedron Lett. 1988, 29, 1777.

44. Harper, M. J. P. Tetrahedron Lett. 1983, 24, 3115.

45. (a) Ginsburg, V. A.; Martynova, L. L.; Lebedeva, M. F.; Dubov, S. S.; Medvedev, A. N.; Tetel'baum, B. F. Zh. Obshch. Khim. 1967, 37, 1073; Chem. Abstr. 1968, 68, 12367. (b) Yakubovich, A. Y.; Gitel, P. O.; Lagutina, Z. N.; Chelobov, F. N. Zh. Obshch. Khim. 1966, 36, 163; Chem. Abstr. 1966, 64, 75389.

46. Makarov, S. P.; Englin, M. A.; Videiko, A. F.; Tobolin, V. A.; Dubov, S. S. Dokl. Akad. Nauk. USSR 1966, 168, 344; Chem. Abstr. 1966, 65, 47137.

47. Hsiao, Y. Y.; Bardos, T. J. J. Med. Chem. 1975, 18, 195.

48. Johnson, M. K. Biochem. Pharm. 1988, 37, 4095. 
49. Blatch, A. J.; Howard, J. A. K.; Probert, M. R.; Smethurst, C. A.; Whiting, A. Acta Cryst. 2006, E62, o5346.

50. Harger, M. J. P. J. Chem. Soc., Perkin Trans. 1 1981, 3284.

51. Klötzer, W.; Stadlwieser, J.; Raneburger, J. Org. Synth. 1986, 64, 96.

52. Masse, G.; Sturtz, G. Synthesis 1988, 907.

53. Banks, M. R.; Hudson, R. F. J. Chem. Soc., Perkin Trans. 2 1989, 463.

54. Callahan, B. P.; Lomino, J. V.; Wolfenden, R. Bioorg. Med. Chem. Lett. 2006, 16, 3802.

55. Przychodzen, W. Eur. J. Org. Chem. 2005, 2002.

56. Wang, L.; Phanstiel IV, O. J. Org. Chem. 2000, 65, 1442.

57. (a) Przychodzen, W.; Chojnacki, J. Heteroatom Chem. 2008, 19, 271. (b) Przychodzen, W. Heteroatom Chem. 2006, 17, 676.

58. Guzzo, P. R.; Teng, M.; Miller, M. J. Tetrahedron 1994, 50, 8275.

59. Hsiao, Y. Y.; Bardos, T. J. J. Med. Chem. 1975, 18, 195.

60. Doi, J. T.; Ma, Q.-F.; Rowley, G. L.; Kenyon, G. L. Med. Chem. Res. 1991, 1, 226.

61. Glabe, A. R.; Sturgeon, K. L.; Ghizzoni, S. B.; Musker, W. K.; Takahashi, J. N. J. Org. Chem. 1996, 61, 7212.

62. (a) Anderson, V. E.; Weiss, P. M.; Cleland, W. W. Biochemistry 1984, 23, 2779. (b) Wedekind, J. E.; Poyner, R. R.; Reed, G. H.; Rayment, I. Biochemistry 1994, 33, 9333.

63. Salomon, C. J.; Breuer, E. J. Org. Chem. 1997, 62, 3858.

64. Bauer, L.; Exner, O. Angew. Chem., Int. Ed. Engl. 1974, 13, 376. 